\title{
BMJ Open Acupuncture-related adverse events: systematic review and meta-analyses of prospective clinical studies
}

\author{
Petra Bäumler (D) , ${ }^{1}$ Wenyue Zhang, ${ }^{2}$ Theresa Stübinger, ${ }^{1}$ Dominik Irnich ${ }^{1}$
}

To cite: Bäumler P, Zhang $W$, Stübinger T, et al. Acupuncturerelated adverse events: systematic review and meta-analyses of prospective clinical studies. BMJ Open 2021;11:e045961. doi:10.1136/ bmjopen-2020-045961

- Prepublication history and additional supplemental material for this paper are available online. To view these files, please visit the journal online. (http://dx.doi.org/10.1136/ bmjopen-2020-045961).

Received 16 0ctober 2020 Accepted 29 July 2021

Check for updates

(c) Author(s) (or their employer(s)) 2021. Re-use permitted under CC BY-NC. No commercial re-use. See rights and permissions. Published by BMJ.

${ }^{1}$ Multidisciplinary Pain Centre, Department of Anaesthesiology, University Hospital LMU Munich, Munich, Germany

${ }^{2}$ School of Acupuncture,

Moxibustion and Tuina, Beijing Rehabilitation Hospital, Beijing University of Chinese Medicine, Beijing, China

Correspondence to Dr Petra Bäumler;

Petra.Baeumler@med.unimuenchen.de

\section{ABSTRACT}

Objective Overview on risks of acupuncture-related adverse events (AEs).

Design Systematic review and meta-analyses of prospective studies.

Data sources PubMed, Scopus and Embase from inception date to 15 September 2019.

Eligibility criteria for selecting studies Prospective studies assessing AEs caused by needle acupuncture in humans as primary outcome published in English or German.

Data extraction and synthesis Two independent researchers selected articles, extracted the data and assessed study quality. Overall risks and risks for different $A E$ categories were obtained from random effects metaanalyses.

Main outcomes Overall risk of minor AEs and serious adverse events (SAEs) per patients and per treatments. Results A total of 7679 publications were identified. Twenty-two articles reporting on 21 studies were included. Meta-analyses suggest at least one AE occurring in $9.31 \%$ (95\% Cl 5.10\% to $14.62 \%, 11$ studies) of patients undergoing an acupuncture series and in $7.57 \%(95 \% \mathrm{Cl}$ $1.43 \%$ to $17.95 \%, 5$ studies) of treatments. Summary risk estimates for SAEs were $1.01(95 \% \mathrm{Cl} 0.23$ to 2.33 , 11 studies) per 10000 patients and $7.98(95 \% \mathrm{Cl} 1.39$ to $20.00,14$ studies) per one million treatments, for AEs requiring treatment $1.14(95 \% \mathrm{Cl} 0.00$ to $7.37,8$ studies) per 1000 patients. Heterogeneity was substantial $\left(1^{2}>80 \%\right)$. On average, $9.4 \mathrm{AEs}$ occurred in 100 treatments. Half of the AEs were bleeding, pain or flare at the needle site that are argued to represent intended acupuncture reaction. AE definitions and assessments varied largely.

Conclusion Acupuncture can be considered among the safer treatments in medicine. SAEs are rare, and the most common minor AEs are very mild. AEs requiring medical management are uncommon but necessitate medical competence to assure patient safety. Clinical and methodological heterogeneity call for standardised AE assessments tools, clear criteria for differentiating acupuncture-related AEs from therapeutically desired reactions, and identification of patient-related risk factors for AEs.

PROSPERO registration number CRD42020151930.

\section{INTRODUCTION}

Acupuncture describes the insertion of fine needles at defined points on the patient's

\section{Strengths and limitations of this study}

- First systematic review on acupuncture-related adverse events (AES) including a risk of bias assessment.

- First meta-analyses on AEs related to acupuncture.

- Complying with Preferred Reporting Items for Systematic Reviews and Meta-Analyses guidelines.

- Combining studies with heterogeneous AE definitions but providing respective sensitivity analyses.

- Causality assessment based on descriptions of AES as available from the included articles.

body for therapeutic or preventive purposes. It is used worldwide with growing popularity. In the European Union, acupuncture was identified as the most frequently provided method of complementary and alternative medicine with 80000 physicians and 16380 non-medical practitioners. ${ }^{1}$ In the UK alone, 2.3 million traditional acupuncture treatments are carried each year. ${ }^{2}$ In the USA, the number of acupuncturists doubled between 2002 and 2012. ${ }^{3}$ The effectiveness of acupuncture is supported by level la evidence, for example, for chronic musculoskeletal pain and headache, ${ }^{4-6}$ postoperative pain, ${ }^{78}$ postoperative nausea and vomiting, ${ }^{9}$ as well as allergic rhinitis. ${ }^{10}$ Furthermore, promising evidence exists for its potential role in the treatment of numerous other indications, such as stroke rehabilitation, ${ }^{11}$ depression, ${ }^{12}$ aromatase inhibitor-induced arthralgia, ${ }^{13}$ and asthma. ${ }^{14}$ Thus, acupuncture offers a non-pharmacological treatment option for various highly prevalent conditions with great disease burden and significant health economic impact. Long-term pharmacological treatment of these conditions is often associated with substantial side effects. ${ }^{15} 16$ Consequently, also risk estimates on acupuncture-related adverse events (AEs) are required for evidence-based risk-benefit considerations that are essential for clinical decision making. 
However, uncertainty remains about acupuncture safety. AEs related to acupuncture are repeatedly and controversially discussed in both scientific literature and public media. An overview of systematic reviews in $2017^{17}$ illustrates that many of the previous reviews on the safety of acupuncture just summarised case reports or case series. In turn, those reviews, including studies that do allow for $\mathrm{AE}$ frequency estimation, such as cohort studies and large randomised controlled trials (RCTs), mostly addressed only certain types of AEs, particular patient groups, restricted acupuncture regimens or certain countries. These data are surely important for clinical decision making in particular cases but leave the overall risk of acupuncture-related AEs in the general population obscure. Additionally, debate exists about differentiating AEs from therapeutically intended reactions that are claimed to form part of the acupuncture treatment. For example, international consensus exists that aggravation of symptoms represents an $\mathrm{AE}$, because disease burden increases. However, transient worsening of symptoms followed by long-term improvements can be interpreted as a so-called healing crisis in complementary and alternative medicine. ${ }^{18}$ In contrast, such consensus is still missing for local reactions, such as small bleedings upon needle withdrawal, needling pain, and flare around the needling site. These are also interpreted as beneficial signs by acupuncture experts and in standard textbooks and have been linked to neurophysiological mechanisms of acupuncture. Accordingly, quality and intensity of these events should be considered when classifying them as $\mathrm{AE} .{ }^{19-21}$

The last review on prospective studies on AEs related to acupuncture with high external validity dates back to $2001,{ }^{22}$ did not meta-analytically summarise AE risk estimates, and did not assess the quality of included studies. In addition, inconsistency and incompleteness of reporting in primary studies hampered the drawing of firm conclusions on acupuncture safety. Since then, various large-scale clinical trials and nationwide surveys on acupuncture safety have been conducted.

Therefore, it was the aim of this review to provide an up-to-date summary of prospective trials that were particularly designed to evaluate AEs related to needle acupuncture with manual or electrical stimulation and in combination with or without moxibustion.

\section{METHODS}

We systematically reviewed prospective studies that reported on acupuncture-related AEs. The protocol has been registered at the International Prospective Register of Systematic Reviews ${ }^{23}$ on 25 September 2019 (registration number CRD42020151930, online supplemental appendix S1). The research checklists according to the Preferred Reporting Items for Systematic Reviews and Meta-Analyses ${ }^{24}$ and according to the guideline of Metaanalysis Of Observational Studies in Epidemiology ${ }^{25}$ are displayed in the online supplemental appendix S2.

\section{Search strategy}

We searched PubMed, Scopus and Embase for articles published before 15 September 2019 by applying the following search strategy: 1: acupuncture; 2: "adverse event"; 3: "adverse events"; 4: "adverse effect"; 5: "adverse effects"; \#1 AND \#2; \#1 AND \#3; \#1 AND \#4; \#1 AND \#5. Additional records were identified from previous reviews on acupuncture-related AEs. ${ }^{17}$ "Acupuncture" and "adverse effects" are medical subject headings (MeSH) terms.

\section{Inclusion and exclusion criteria}

We included articles reporting on prospective studies (cohort studies, RCTs, surveys or surveillances) assessing AEs associated with needle acupuncture involving manual or electrical stimulation combined with or without moxibustion in humans as their primary outcome. Case reports and case series were not included. Only articles published in English or German were included. Publications on assessments of acupuncture point injection therapies or non-penetrating acupuncture point stimulation, such as laser acupuncture, acupressure or transcutaneous electrical nerve stimulation, were excluded. We also excluded articles reporting solely on moxibustion or restricted acupuncture regimens, such as press-needle, auricular, or one-point acupuncture. Trials focusing just on one type of acupuncture-related $\mathrm{AE}$ or just on a narrowly defined patient population were excluded.

\section{Article selection and data extraction}

Article selection was performed independently by two reviewers ( $\mathrm{WZ}$ and $\mathrm{PB}, \mathrm{TS}$ and $\mathrm{PB}$, or $\mathrm{LM}$ and $\mathrm{PB}$ ). Retrieved records were first screened for eligibility by abstract. Full texts were obtained for the remaining articles. Final decision about eligibility was obtained by consensus of all four reviewers.

Estimates of overall risks and risks for each reported type of AEs were extracted as absolute numbers of patients with $\mathrm{AE}$ per total number of patients and treatments with AE per total number of treatments. Data concerning AEs from sham-acupuncture or placebo-acupuncture treatments were not extracted. The different types of AEs were assigned to one of the following categories: bleeding, local pain, other local $\mathrm{AE}$, distant pain, central nervous system, peripheral nervous system, vegetative nervous system, motor system, gastrointestinal/gynaecological system, cardiovascular system, respiratory system, generalised skin reactions, headache, emotional interference, sleeping problems, AE related to moxibustion, needling malpractice, aggravation of symptoms, and other or unclassified AE (online supplemental appendix S3).

Following the differentiation between AEs and adverse drug reactions defined by the International Conference on Harmonisation (ICH) of Good Clinical Practice, ${ }^{26}$ articles were classified into reports on AEs irrespective of their causal relationship to acupuncture and adverse reactions for which a causal relationship was a reasonable possibility. Serious adverse events (SAEs) were reported as 
indicated in the included articles in accordance with the ICH criteria. These include any untoward medical occurrence that at any dose results in death, is life-threatening, requires inpatient hospitalisation or prolongation of existing hospitalisation, results in persistent or significant disability/incapacity or is a congenital anomaly/birth defect. ${ }^{26} \mathrm{AE}$ definitions and severity assessments as stated in the included publications are provided in the online supplemental appendix S4. Causality assessment of SAEs was performed by independent acupuncture therapists who were medical doctors with more than 300 hours of acupuncture training and with more than 10 years of intensive acupuncture practice. As the basis of this assessment was limited to incomplete information provided in the articles, for example, lacking time references, the standard categories of the WHO-UMC (Uppsala Monitoring Centre) causality assessment system ${ }^{27}$ were reduced to 'possibly related to acupuncture', 'unlikely related to acupuncture', or 'unclassifiable'. AE risk estimates given as patients with $\mathrm{AE}$ per total number of patients were interpreted according to the guidelines of the Council for International Organisations of Medical Sciences as very common $(\geq 1 / 10$ patients), common $(\geq 1 / 100$ to $<1 / 10)$, uncommon $(\geq 1 / 1000$ to $<1 / 100)$, rare $(\geq 1 / 10000$ to $<1 / 1000)$ or very rare $(<1 / 10000) .^{28}$

Documentation of study characteristics included the study type, the country in which the study was conducted, the reporter, the method and the time point of $\mathrm{AE}$ assessment, complaints as well as the age and the gender structure of the study population, the average number and the frequency of treatments per patient, the average number of needles per treatment, the needle in time, the acupuncture style, the method of needle stimulation, and the number, the gender, the training, and years of experience of acupuncturists. Data on patients' and acupuncturists' $\mathrm{AE}$ reports from the article published by Weidenhammer et al in 2008 were handled as two separate trials.

\section{Risk of bias assessment}

Included studies were assessed for risk of bias according to a checklist developed by Faillie and colleagues for systematic reviews focusing on drug AEs. ${ }^{29}$ This checklist is applicable to RCTs, cohort studies, case-control studies, nested case-control studies, and systematic reviews. The questions are structured in eight risk of bias domains. Possible answers are 'not applicable', 'yes', 'unclear' or 'no'. A summary risk of bias assessment is provided for each domain as well as for the whole study. According to the inclusion criteria of this review, questions concerning systematic reviews, cross-over trials, and case-control studies were not applicable.

\section{Data analysis}

Data were analysed using the package meta implemented in $\mathrm{R}^{30}$ Pooled estimates with $95 \%$ CIs for overall AE risk and risks of different types of AEs were obtained from proportion meta-analyses. Random effects models were calculated by the Hartung-Knapp method with arcsine transformation of proportions. Cochran $\mathrm{Q}$ test, and $\mathrm{I}^{2}$ statistics were used to assess the heterogeneity of included studies. Meta-analyses were performed for the overall risks for an $\mathrm{AE}$, for an $\mathrm{SAE}$, for an $\mathrm{AE}$ requiring treatment, and the risks for the different types of AEs. Separate meta-analyses were conducted for $\mathrm{AE}$ risks given as the number of patients with $\mathrm{AE}$ per total number of patients undergoing an acupuncture series and $\mathrm{AE}$ risks given as the number of treatments with $\mathrm{AE}$ per total number of treatments performed. All studies reporting the respective risks were included in the different meta-analyses. All AEs that were reported separately in the articles but were allocated to the same AE category were treated as they had occurred in different patients or treatments, respectively. Sensitivity analyses were performed for studies that explicitly only reported about AE that had, at the discretion of the assessors, a causal relationship to acupuncture treatments. None of the articles reported the mean and variance of the number of AEs per treatment. Thus, the expected number of AEs per treatment could not be estimated by means of a meta-analysis but just by considering the sum of AE relative to the sum of treatments. An additional sensitivity analysis was performed by excluding AEs that are usually very mild and transient or are often argued to be part of the treatment or a desired treatment response, such as transient bleeding, needle site pain or a flare around the needle insertion point. AEs that were indicated by any means as significant were not excluded from this sensitivity analysis.

\section{Patient and public involvement}

No patients were involved in defining the research question, the outcome measures, the design, or conduct of this review. No patients were asked to advise on interpretation of results. Authors will share the results during patient seminars and information events. A concise version of the results will be made available for non-profit acupuncture organisations to be presented on their web pages.

\section{RESULTS}

\section{Study characteristics}

A total of 7679 records were retrieved from the database search and two were identified from previous reviews on acupuncture-related AEs. A total of 7499 records could be screened by abstract, and for 180 articles full texts were obtained. A total of 22 articles reporting on 21 studies covering 12.9 million treatments met our inclusion criteria (figure 1) ${ }^{31-52}$ In two studies, different data assessments on different subpopulations were performed and are treated independently in the present analyses. In one study, patient-reported AEs were assessed after one of the first treatments and three months after treatment, ${ }^{38} 39$ and in one large study, AEs were documented by therapists and in addition by a subgroup of patients. ${ }^{46}$

Study characteristics are provided in table 1 . The four largest trials, which included 100000 to 500000 patients 


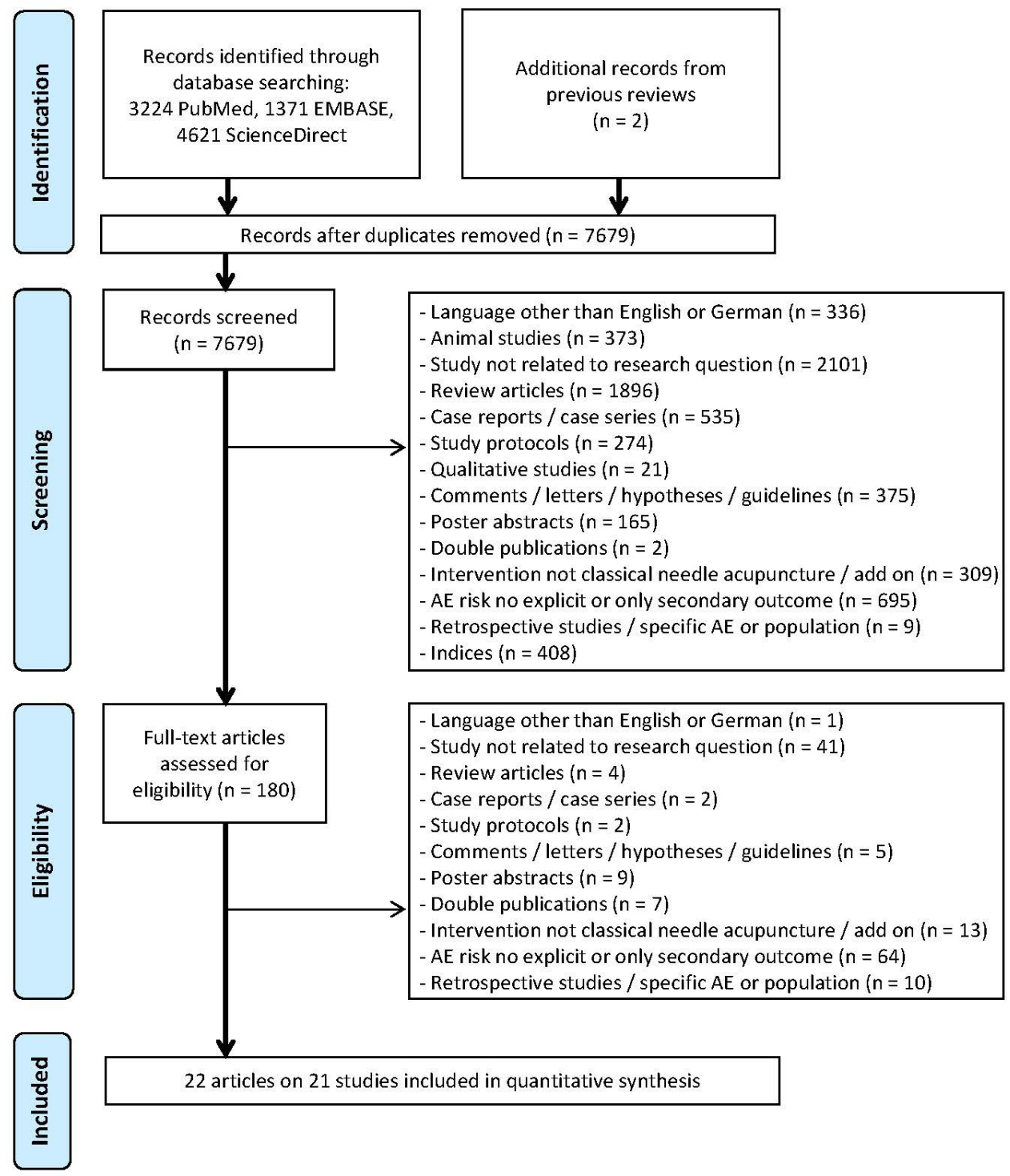

Figure 1 Flow diagram. designed according to the Preferred Reporting Items for Systematic Reviews and Meta-Analyses. ${ }^{24}$ AE, adverse event.

treated in over 750000 acupuncture sessions, were cohort studies performed as part of the German Model Projects on Acupuncture (Modellvorhaben Akupunktur). ${ }^{33} 414649$ Three nationwide surveys from the UK (described in four articles), ${ }^{38-40} 48$ one in-house surveillance report from Japan, ${ }^{51}$ and one summary of AE assessments nested within three Chinese RCTs ${ }^{52}$ included 2000-6000 patients receiving over 30000 treatments, respectively. In three surveys, two from South Korea, ${ }^{44}$ one from Japan, ${ }^{35}$ and one from Brazil, ${ }^{32}$ around 1000-2000 patients were included and treated in up to 14000 acupuncture sessions. One nationwide survey conducted in Sweden assessed the AE risk based on data from over 9000 acupuncture sessions. ${ }^{43}$ In seven studies, less than 500 patients receiving a maximum of 3500 treatments were included: four AE assessments nested within RCTs or clinical trials from China, ${ }^{47}$ Hong Kong, ${ }^{31} 36$ and Sweden, ${ }^{37}$ one Japanese ${ }^{50}$ and one German survey, ${ }^{34}$ as well as one German cohort study. ${ }^{42}$ In most studies, acupuncture was used to treat pain in middle-aged patients. In six articles, no details on the patients' condition were provided. ${ }^{343540434850}$ Two articles reported explicitly on short-term AEs after one particular treatment only. ${ }^{3945}$ All but five articles provided sufficient information to infer that acupuncturists had a firm medical background and/ or had received intensive acupuncture training. ${ }^{3436374243}$ One German survey also included 'other practitioners' most likely non-medical practitioners (Heilpraktiker) with non-standardised acupuncture training. ${ }^{34}$

Eight articles described AEs reported by patients only, ${ }^{31} 32 \quad 37-39454649$ and seven articles described AEs reported by acupuncturists only. ${ }^{33} 404144464851$ As said before, Weidenhammer et al described therapists' and patients' AE reports separately. ${ }^{46}$ Zhao et al combined the AE reports from patients and acupuncturists. ${ }^{52}$ In five articles, it was explicitly stated that acupuncturists recording the AEs also queried their patients about any uncomfortable experience during or after treatment. ${ }^{34-36} 4350$ 


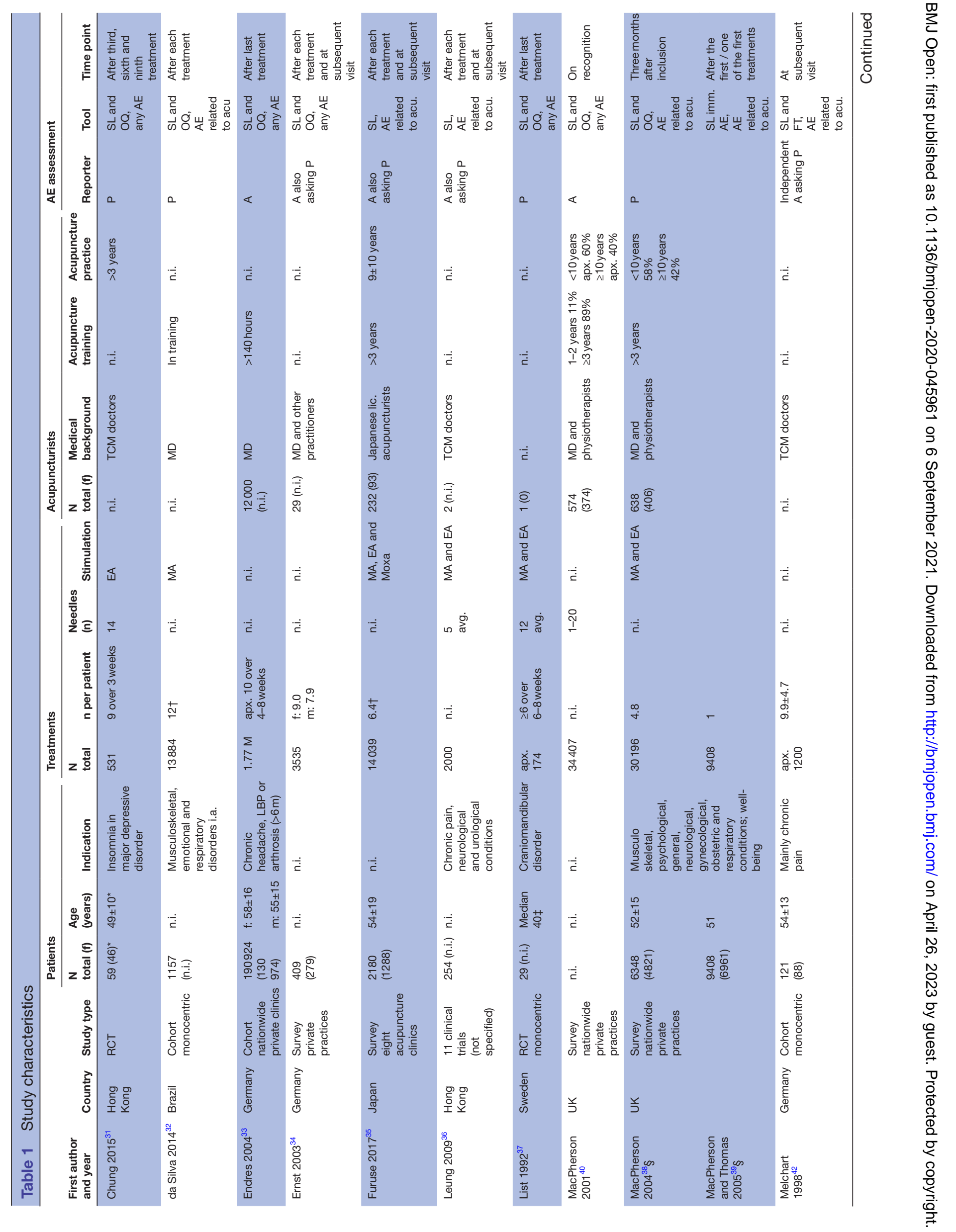



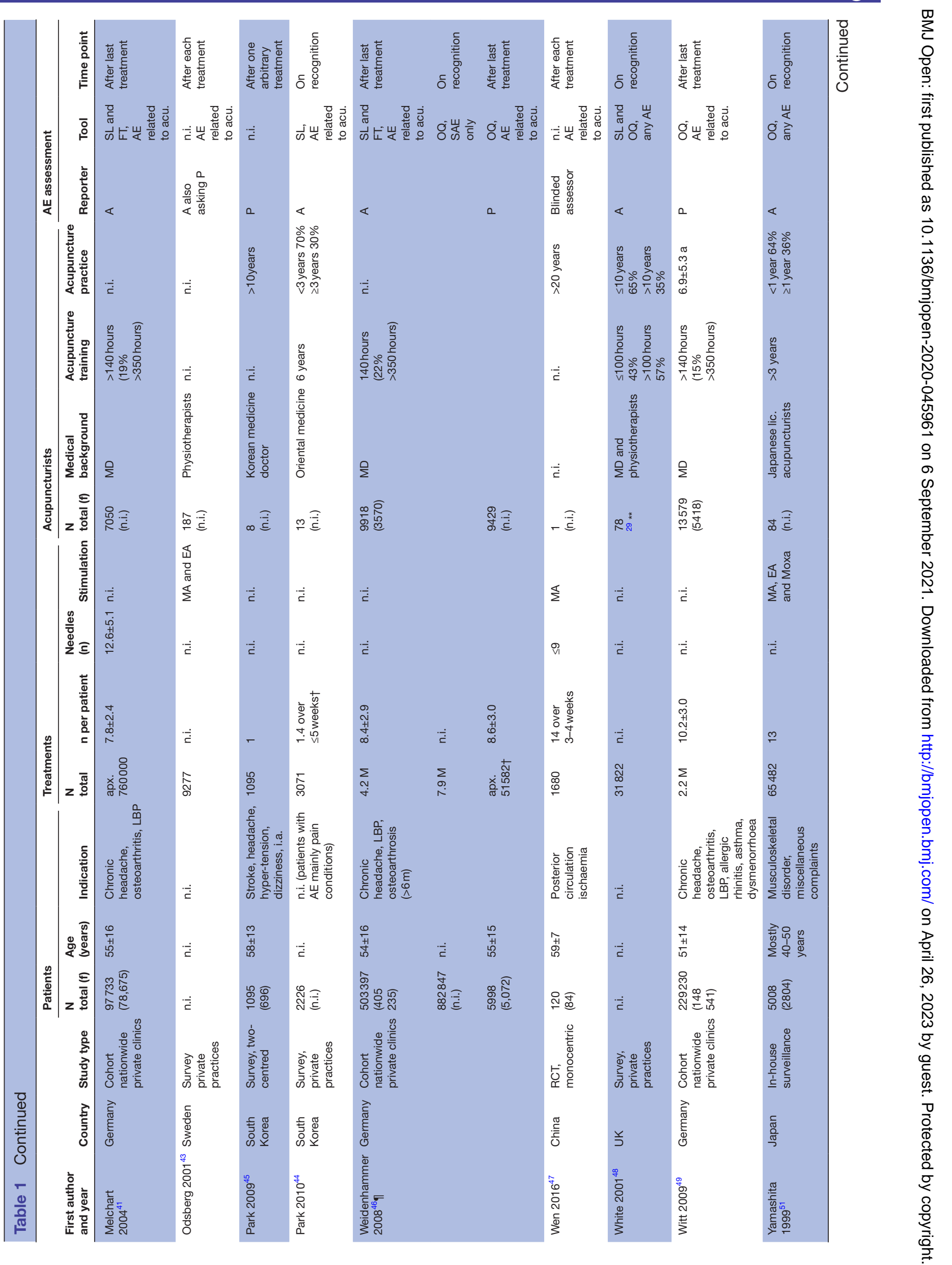


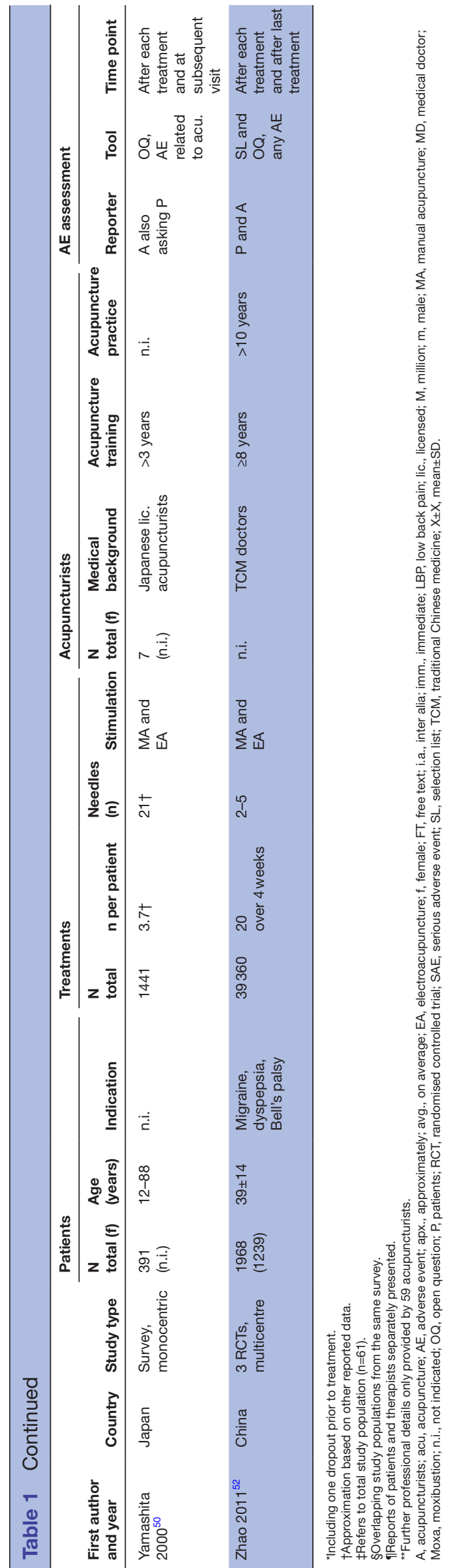

In two trials, AEs were documented by an independent assessor. ${ }^{42}{ }^{47}$ In eight of the 22 included articles, AEs were reported irrespective of their relationship to acupuncture,,$^{31} 33343740485152$ while descriptions of AE assessments in 14 articles suggest that only AEs related to the acupuncture treatment were documented, ${ }^{31} 323536383941-4446474950$ and one article did not provide information about the $\mathrm{AE}$ definition. ${ }^{45}$ Further discrepancies were found in definitions of certain reactions as therapeutically intended. For example, da Silva et al did not count aggravation of symptoms as an AE because of difficulties in determining causality as well as severity and because of a common notion among practitioners that transient worsening forms part of the acupuncture treatment. ${ }^{32}$ In contrast, White et al reported aggravated symptoms as $\mathrm{AE}$, but only those that were not followed by substantial improvements. ${ }^{48}$ The other articles did not specify aggravation of symptoms further. ${ }^{33-35} 373842464950$ In addition, Endres $e t$ $a l$ did report on erythema at the needling site (which was accounted for in the present analysis) but did not include this in their overall AE incidence report, as it can also be regarded as a desired acupuncture reaction. ${ }^{33}$

\section{Risk of bias assessment}

According to the inclusion criteria, the study objective was clearly described in all articles (figure 2, category A). Study design was clear for all but one article, which stated that data were collected in the course of eleven clinical trials without further specification. ${ }^{36}$ Furthermore, all but one $\mathrm{AE}$ assessment were free of a run-in period. In one RCT, the safety assessment was initiated with a short delay. ${ }^{37}$ Both irregularities were rated as unlikely to introduce bias into the AE documentation. High risk of selection bias (figure 2, category B) was identified in the four RCTs and the AE assessment in eleven clinical trials (23\% of articles) due to exclusion of patients with comorbidities or bleeding tendency. In contrast, in all surveys and cohort studies $(77 \%)$, the risk of selection bias was rated as unclear due to an indistinct selection of therapists and/or patients, inclusion of voluntarily participating acupuncturists or acupuncturists from specialised medical centres only. Furthermore, none of the articles stated that patients were naive to acupuncture. Risk of bias due to study withdrawal or drop-out (figure 2, category $\mathrm{C}$ ) was rated as low for all RCTs and two surveys, which reported only on short-term AEs (27\%), ${ }^{39}$ and as high for one survey $(5 \%)$, because treatment was ceased for $40 \%$ of the patients with $\mathrm{AE}^{44}$ For the remaining studies (68\%), the risk of bias due to early treatment termination was rated as unclear, as withdrawals and drop-outs due to $\mathrm{AE}$ were not reported. The risk of information bias regarding the safety outcome (figure 2, category D) was rated as high for one study $(5 \%)$ because of an exclusive documentation of repeatedly occurring $\mathrm{AEs}^{37}$ and as unclear for all remaining studies (95\%). At this, AE reporting by patients or acupuncturists instead of an independent assessor was classified as an unclear risk of social desirability bias. Further possible but unclear sources of detection bias 
A

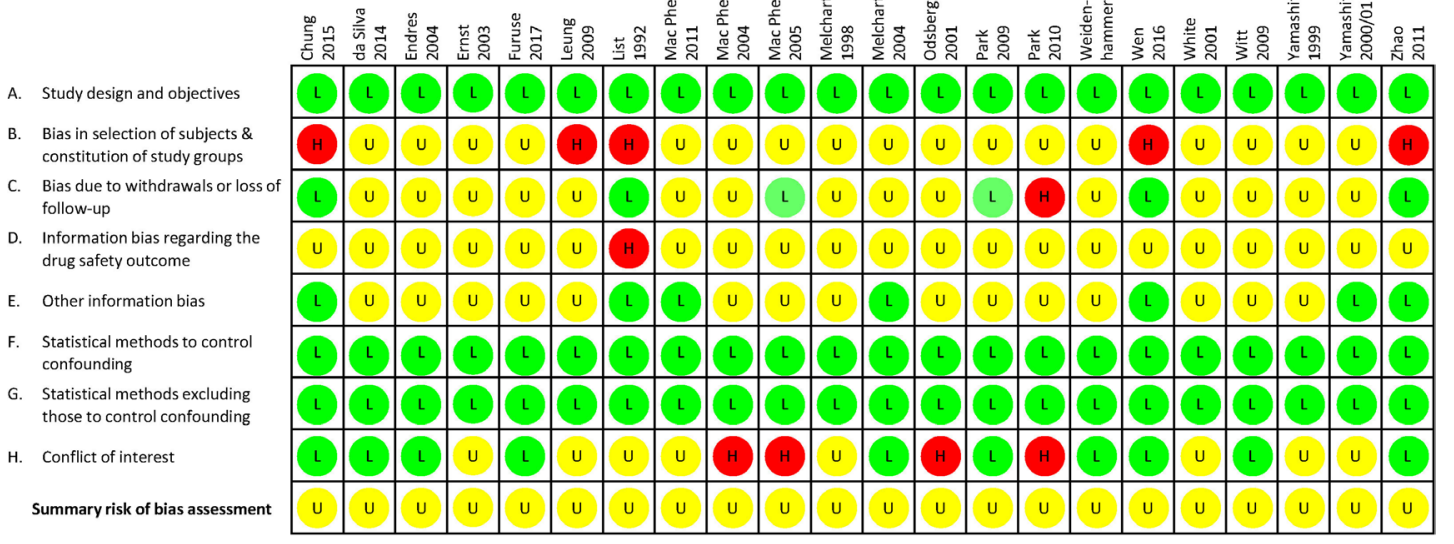

B

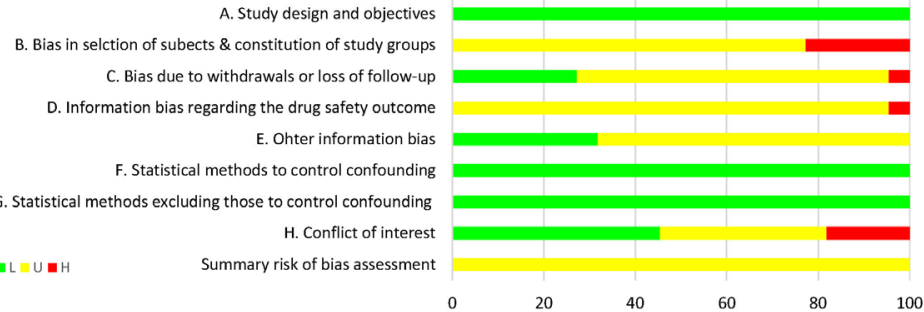

Figure 2 Risk of bias assessment. Risk of bias assessment was conducted according to Faillie et al. ${ }^{29} \mathrm{~L}$, green (low risk of bias); $\mathrm{U}$, yellow (unclear risk of bias); $\mathrm{H}$, red (high risk of bias).

were the sole use of a selection list ${ }^{35} 363944$ or the sole use of open questions as $\mathrm{AE}$ assessment tool, ${ }^{4-51}$ lack of reporting on the $\mathrm{AE}$ assessment tool, ${ }^{43} 4547$ and unclear definition of the safety outcome and/or the time point of the $\mathrm{AE}$ assessment (only directly after treatment, ${ }^{32} 334347$ only after the last treatment initiation, ${ }^{3738414649}$ and solely on recognition ${ }^{40} 4451$ ). Further risk of information bias (figure 2, category E) appeared to be unclear due to poor reporting of treatment details in all but seven studies (32\%). ${ }^{31} 374041475052$ Bias arising from differential care, confounder assessment and statistical methods to control for confounding (figure 2, category F) was rated as low, as crude $\mathrm{AE}$ risk estimates and not relative risks with respect to a comparator group were extracted. The risk of bias due to other statistical methods (figure 2, category $\mathrm{G}$ ) was also rated as low, as reporting of AE incidence was clear and well structured in all articles.

Bias due to conflict of interest (figure 2, category $\mathrm{H}$ ) might be present in four articles (18\%) due to funding by institutions with direct interest in the public acknowledgement of acupuncture. ${ }^{38} 394344$ In eight articles $(36 \%)$, funding or other conflicts of interest were not described. ${ }^{34} 36374042485051$ The 10 remaining articles (45\%) included an explicit statement about funding by independent institutions and the absence of other conflicts of interest. For all studies, the overall risk of bias was rated as unclear based on the large proportion of unclear sources of bias.

\section{Overall risk of acupuncture-related AEs}

Eleven studies including 845637 patients that assessed the overall $\mathrm{AE}$ risk as patients with $\mathrm{AE}$ among the total number of patients undergoing an acupuncture series were combined in a meta-analysis. The overall risk of at least one $\mathrm{AE}$ during a series of acupuncture treatments was estimated to be 9.31 (95\% CI 5.10 to 14.62 ) per 100 patients treated (figure 3A). ${ }^{31} 343638414246474952$ The median number of treatments per patient was nine (min 4.8, max 14), and the total number of treatments exceeded 7.4 million. Visual inspection indicated an association of the incidence of AEs neither with the number of treatments per acupuncture series nor with the study type (online supplemental appendix S5). Five studies reported the total number of acupuncture treatments with AE relative to the total number of treatments performed. ${ }^{3234364042}$ Meta-analysis of these studies covering 55026 treatments in total resulted in a risk of 7.57 (95\% CI 1.43 to 17.95) treatments with AE per 100 treatments (figure 3B). Sensitivity analysis of studies reporting on adverse acupuncture reactions and not on AEs irrespective of their relationship to acupuncture treatments resulted in similar estimates $^{32} 36384041464749$ : 8.23 (95\% CI 6.42 to 10.25 ) patients with at least one $\mathrm{AE}$ per 100 patients (figure $3 \mathrm{C}$ ) and 6.08 (95\% CI 0.00 to 38.76) treatments with AE per 100 treatments (figure 3D). Heterogeneity for all meta-analyses mentioned previously (including the sensitivity analyses) was substantial as indicated by an $\mathrm{I}^{2}$ between $98 \%$ and $100 \%(\mathrm{p}<0.01)$.

Thirteen articles reported the incidences of different types of AEs per treatment (table 2). ${ }^{32} 34-36394042-45485051$ The average number of AEs per 100 treatments varied between 0.14 and 69.12. In total, 18002 AEs were reported in 190661 treatments, which makes on average 9.44 AEs 
A Overall AE risk among patients undergoing an acupuncture series

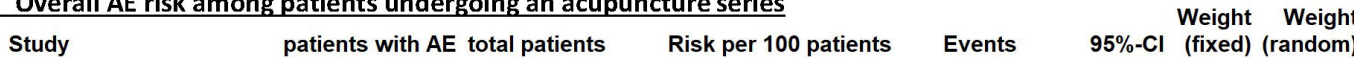

Chung 2015

Wen 2016

Melchart 1998

Leung 2009

Ernst 2003

Zhao 2011

Weidenhammer 2008 pat.

MacPherson 2004

Melchart 2004

Witt 2009

Weidenhammer 2008 ther.

Fixed effect model

Random effects model

Heterogeneity: $I^{2}=99 \%, \tau^{2}=0.0004, p<0.01$

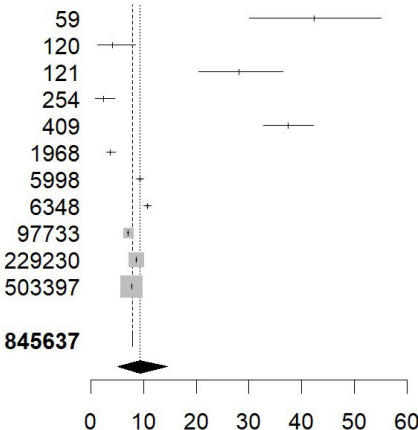

$42.37[30.15 ; 55.09] \quad 0.0 \% \quad 1.2 \%$

$4.17[1.34 ; 8.45] \quad 0.0 \% \quad 2.3 \%$

$28.10[20.48 ; 36.41] \quad 0.0 \% \quad 2.3 \%$

$2.36 \quad[0.86 ; 4.58] \quad 0.0 \% \quad 4.2 \%$

$37.41[32.79 ; 42.15] \quad 0.0 \% \quad 5.8 \%$

$3.76[2.97 ; 4.65] \quad 0.2 \% \quad 11.3 \%$

$9.34[8.61 ; 10.09] \quad 0.7 \% \quad 13.7 \%$

$10.74[9.99 ; 11.52] \quad 0.8 \% \quad 13.7 \%$

$7.10 \quad[6.94 ; 7.26] \quad 11.6 \% \quad 15.1 \%$

$8.61[8.49 ; 8.72] \quad 27.1 \% \quad 15.1 \%$

$7.76[7.69 ; 7.84] \quad 59.5 \% \quad 15.2 \%$

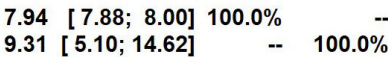

B Overall AE risk per acupuncture treatment

Study treatments with AE total treatments Risk per 100 treatments

Events $\quad 95 \%-\mathrm{Cl} \quad \begin{aligned} & \text { Weight } \\ & \text { (fixed) }\end{aligned} \begin{array}{r}\text { Weight } \\ \text { (random) }\end{array}$

Melchart 1998

Leung 2009

Ernst 2003

da Silva 2014

MacPherson 2001

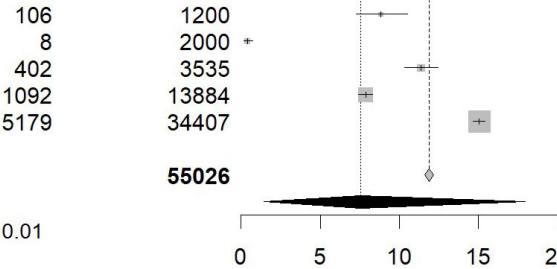

$8.83 \quad[7.29 ; 10.50] \quad 2.2 \% \quad 19.8 \%$

$0.40 \quad[0.17 ; 0.72] \quad 3.6 \% \quad 19.9 \%$

$11.37[10.35 ; 12.44] \quad 6.4 \% \quad 20.0 \%$

$7.87 \quad[7.42 ; 8.32] \quad 25.2 \% \quad 20.1 \%$

$15.05[14.68 ; 15.43] \quad 62.5 \% \quad 20.2 \%$

Fixed effect model

Random effects model

Heterogeneity: $I^{2}=100 \%, \tau^{2}=0.0103, p<0.01$

$11.88[11.61 ; 12.15] 100.0 \% \quad r-$

C Overall risk for AE related to acupuncture among patients undergoing a treatment series

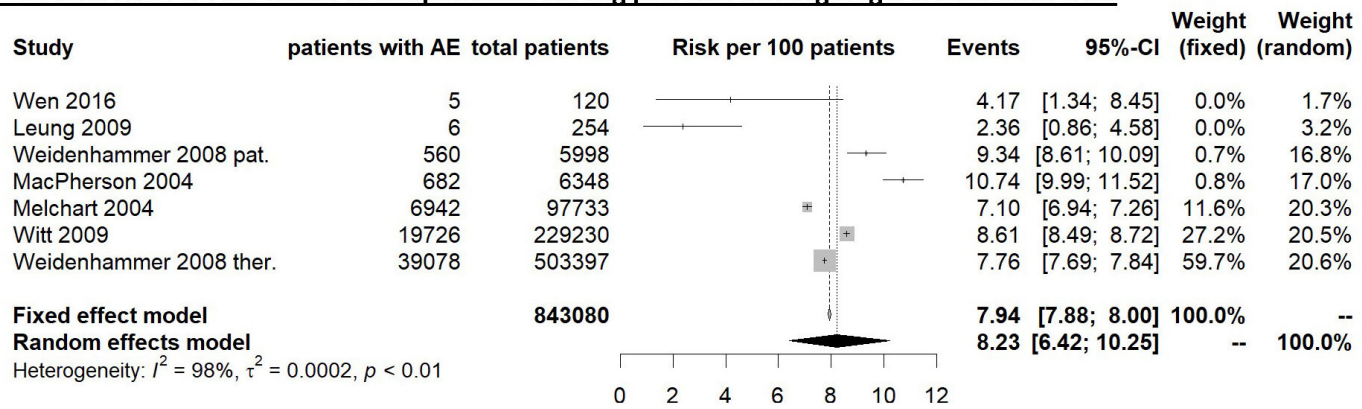

D Overall risk for AE related to acupuncture per treatment

\begin{tabular}{|c|c|c|c|c|c|c|c|c|}
\hline \multirow{2}{*}{$\begin{array}{l}\text { Study } \\
\text { Leung } 2009\end{array}$} & \multicolumn{2}{|c|}{ treatments with $A E$ total treatments } & \multicolumn{2}{|c|}{ Risk per 100 treatments } & \multirow{2}{*}{$\begin{array}{r}\text { Events } \\
0.40\end{array}$} & \multirow{2}{*}{$\begin{array}{r}95 \%-\mathrm{Cl} \\
{[0.17 ; 0.72]}\end{array}$} & \multicolumn{2}{|c|}{ (fixed) (random) } \\
\hline & 8 & $2000 *$ & & & & & $4.0 \%$ & $33.1 \%$ \\
\hline da Silva 2014 & 1092 & 13884 & + & & 7.87 & {$[7.42 ; 8.32]$} & $27.6 \%$ & $33.4 \%$ \\
\hline MacPherson 2001 & 5179 & 34407 & & + & 15.05 & {$[14.68 ; 15.43]$} & $68.4 \%$ & $33.4 \%$ \\
\hline \multirow{2}{*}{\multicolumn{2}{|c|}{$\begin{array}{l}\text { Fixed effect model } \\
\text { Random effects model }\end{array}$}} & 50291 & & 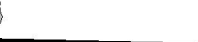 & \multirow{3}{*}{$\begin{array}{r}11.99 \\
6.08\end{array}$} & \multirow{3}{*}{$\begin{array}{r}{[11.71 ; 12.28]} \\
{[0.00 ; 38.76]}\end{array}$} & \multirow{3}{*}{$\begin{array}{r}100.0 \% \\
--\end{array}$} & \multirow{3}{*}{$100.0 \%$} \\
\hline & & & & & & & & \\
\hline \multicolumn{2}{|c|}{ Heterogeneity: $I^{2}=100 \%, \tau^{2}=0.0133, p<0.01$} & 0 & 10 & 30 & & & & \\
\hline
\end{tabular}

Figure 3 Meta-analyses of the overall risk of acupuncture-related AEs. Summary risk estimates for AEs were calculated as the number of patients or treatments with at least one AE relative to the total number of patients or treatments, respectively. Data on $\mathrm{AE}$ reports of patients and therapists from the article published by Weidenhammer et al in $2008^{46}$ were handled separately. $\mathrm{AE}$, adverse event.

per 100 treatments. Exclusion of AEs that are usually mild and transient or are often argued to be part of the treatment or a desired treatment response, such as transient bleeding, needle site pain or a flare around the needle insertion point, reduced this number to 4.81 ( $\min 0.10$, max 36.92) AEs per 100 treatments.

\section{Serious acupuncture-related AEs}

SAEs were observed in five studies including 1182860 patients undergoing 10570678 treatments with incidences between two and 47 SAEs in 100000 patients undergoing a treatment series and between two and 99 in one million treatments, respectively. ${ }^{33} 38414651$ Four articles reported that none of the AEs observed in a total of 1922 patients undergoing 19005 treatments required medical treatment, ${ }^{32} 364750$ and authors of five articles concluded that none of the AEs observed in 122699 treatments fulfilled the ICH criteria for SAE..$^{35} 40444852$ Eight articles did not mention SAEs or any AE description that allowed for inferences about SAEs. ${ }^{31} 34373942434549$

Meta-analyses of the overall risk of an SAE resulted in 1.01 (95\% CI 0.23 to 2.33) patients with an SAE in 10000 patients undergoing an acupuncture series (figure 4A 11 studies, 1188930 patients) and 7.98 (95\% CI 1.39 to 20.00) SAEs in one million treatments (figure $4 \mathrm{~B}$ and 1 
Table 2 Number of AEs per treatment

\begin{tabular}{|c|c|c|c|c|c|c|}
\hline \multirow[b]{2}{*}{ Study } & \multirow[b]{2}{*}{ Treatments (n) } & \multicolumn{2}{|l|}{ AEs (n) } & \multicolumn{2}{|c|}{$\begin{array}{l}\text { AE incidence per } 100 \\
\text { treatments }\end{array}$} & \multirow{2}{*}{$\begin{array}{l}\text { Bleeding, pain } \\
\text { and flare at } \\
\text { needling site } \\
\text { as } \% \text { of all } \mathrm{AE}\end{array}$} \\
\hline & & Total & $\begin{array}{l}\text { Excluding bleeding, } \\
\text { pain, and flare }\end{array}$ & Total & $\begin{array}{l}\text { Excluding } \\
\text { bleeding, pain, } \\
\text { and flare }\end{array}$ & \\
\hline Park et al $2009^{45}$ & 1095 & 193 & 64 & 17.63 & 5.84 & $66.84 \%$ \\
\hline Ernst et al $2003^{34}$ & 3535 & 632 & 403 & 17.88 & 11.40 & $36.23 \%$ \\
\hline Yamashita et al $2000^{50}$ & 1441 & 996 & 114 & 69.12 & 7.91 & $88.55 \%$ \\
\hline MacPherson et al $2001^{40}$ & 34407 & 4544 & 3406 & 13.21 & 9.90 & $25.04 \%$ \\
\hline Odsberg et al $2001^{43}$ & 9277 & 2108 & 390 & 22.72 & 4.20 & $81.50 \%$ \\
\hline White et al $2001^{48}$ & 31822 & 2176 & 820 & 6.84 & 2.58 & $62.32 \%$ \\
\hline da Silva et al $2014^{32}$ & 13884 & 1107 & 117 & 7.97 & 0.84 & $89.43 \%$ \\
\hline Furuse et al $2017^{35}$ & 14039 & 854 & 232 & 6.08 & 1.65 & $72.83 \%$ \\
\hline Overall & 190661 & 18002 & 9178 & 9.44 & 4.81 & $49.02 \%$ \\
\hline
\end{tabular}

$\mathrm{AE}$, adverse event.

study, 10712382 treatments). Exclusion of studies with zero SAE incidences changed these estimates to 1.47 (95\% CI 0.10 to 4.46 ) in 10000 patients suffering from an SAE when undergoing an acupuncture series and 16.90 (95\% CI 0.49 to 56.60) SAEs in one million treatments. Sensitivity analyses of studies that only reported reactions with a plausible relationship to acupuncture resulted in risk estimates of 0.45 (95\% CI 0.06. to 1.18) SAEs per 10000 patients (figure 4C) and 5.45 (95\% CI 0.50 to 15.67 ) per one million treatments (figure $4 \mathrm{D}$ ). Again, heterogeneity between studies included in these two meta-analyses was substantial $\left(\mathrm{I}^{2}>85 \%, \mathrm{p}<0.001\right)$.

The causality assessment of the 73 SAEs conducted by two acupuncture experts (table 3) resulted in 32 SAEs (44\%) being possibly related to acupuncture. Among those, pneumothorax, strong cardiovascular or vasovagal reactions, and fall or trauma were the most frequent SAEs with a frequency of one to three cases in one million treatments each. One article that was not taken into account in the SAE meta-analyses, because observed AEs were not categorised in minor AEs and SAEs, also reported two cases of pneumothorax in over 200000 patients undergoing on average 10 acupuncture treatments. ${ }^{49}$ Nineteen SAEs $(26 \%)$ were rated as unlikely related to acupuncture. Among those were nine deaths observed in one large study among patients aged between 67 and 87 years and related to pre-existing health conditions. ${ }^{33}$ Authors reported that the resulting death rate of 4.71 per 100000 patients was below the expected death rate derived from population statistics. Other SAEs classified as unlikely related to acupuncture were a circulatory reaction with amnesia, suicidal tendencies, acute general infection, a car crash two days after treatment, a malignant parotid tumour, tonic-clonic seizures, and an ophistotonus. Twenty-two SAEs (30\%), intervertebral disk prolapses and hospitalisations due to pain exacerbation or unknown reasons, were rated as 'unclassifiable'.

\section{Acupuncture-related AEs requiring treatment}

Eight studies determining the number of patients with AEs requiring treatment during an acupuncture series included 1211791 patients. The meta-analysis of these studies yielded a summary estimate of 1.14 (95\% CI 0.00 to 7.37 ) in 1000 patients for the risk to suffer from an $\mathrm{AE}$ that required treatment when undergoing an acupuncture series (figure 5). ${ }^{3132364146474950}$ Also here, heterogeneity was substantial $\left(\mathrm{I}^{2}\right.$ of $\left.100 \%\right)$. Two articles that had defined requirement of treatment as an SAE criterion reported lower incidences ( 2 and 6 events per 100000 patients $)^{4146}$ than the other two articles reporting on AEs requiring treatment without referring to SAEs (1.7 and 2.2 in 100 patients). ${ }^{31} 49$

\section{Risks of different types of minor AEs}

Overall risks of the different types of minor AEs (for categorisation, see online supplemental appendix S3) were estimated in separate meta-analyses as patients with such AE per total number of patients undergoing a treatment series or as treatments with such AE per total number of treatments (table 4). Risks estimated in single studies (online supplemental appendices S6 and S7) varied largely for all types of minor AEs. Most frequent and commonly occurring minor AEs with summary risk estimates between $1 \%$ and $5 \%$ of patients undergoing 
A Overall SAE risk among patients undergoing an acupuncture series

Wen 2016

Leung 2009

Yamashita 2000

da Silva 2014

Zhao 2011

Furuse 2017

Yamashita 1999

MacPherson 2004

Melchart 2004

Endres 2004

Weidenhammer 2008 ther

patients with SAE total patients Risk per 10000 patients

Events

$95 \%-\mathrm{Cl}$ (fixed) (random)

Fixed effect model

Random effects model

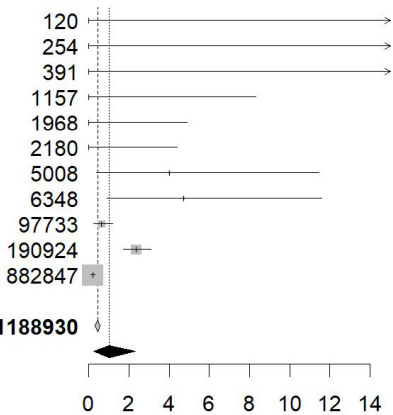

$0.00[0.00 ; 79.82] \quad 0.0 \% \quad 0.4 \%$

$0.00[0.00 ; 37.76] \quad 0.0 \% \quad 0.8 \%$

$0.00[0.00 ; 24.54] \quad 0.0 \% \quad 1.2 \%$

$0.00[0.00 ; 8.30] \quad 0.1 \% \quad 3.3 \%$

$0.00[0.00 ; 4.88] \quad 0.2 \% \quad 5.1 \%$

$0.00[0.00 ; 4.40] \quad 0.2 \% \quad 5.5 \%$

$3.99[0.38 ; 11.44] \quad 0.4 \% \quad 9.5 \%$

$4.73[0.89 ; 11.58] \quad 0.5 \% \quad 10.8 \%$

$0.61 \quad[0.22 ; 1.20] \quad 8.2 \% \quad 20.5 \%$

$2.36[1.72 ; 3.10] \quad 16.1 \% \quad 21.1 \%$

$0.19[0.11 ; 0.29] \quad 74.3 \% \quad 21.6 \%$

Heterogeneity: $I^{2}=88 \%, \tau^{2}<0.0001, p<0.01$

$\begin{array}{rrr}0.43[0.32 ; 0.56] & 100.0 \% & - \\ 1.01[0.23 ; 2.33] & -- & 100.0 \%\end{array}$

B Overall SAE risk per acupuncture treatment

Study

treatments with SAE total treatments Risk per $1 \mathrm{e}+06$ treatments Events

Weight Weight
$95 \%-\mathrm{Cl}$ (fixed) (random)

Yamashita 2000

Wen 2016

Leung 2009

Park 2010

da Silva 2014

Furuse 2017

MacPherson 2004

White 2001

MacPherson 2001

Zhao 2011

Yamashita 1999

Melchart 2004

Endres 2004

Weidenhammer 2008 ther

Fixed effect model

Random effects model

Heterogeneity: $I^{2}=85 \%, \tau^{2}<0.0001, p<0.01$

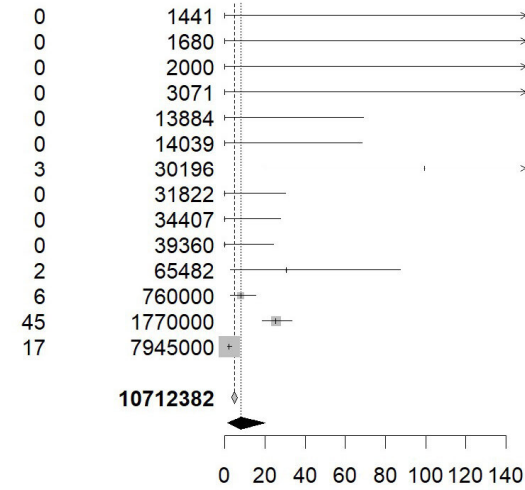

$0.00[0.00 ; 666.31] \quad 0.0 \% \quad 0.4 \%$ $0.00[0.00 ; 571.54] \quad 0.0 \% \quad 0.5 \%$ $0.00[0.00 ; 480.11] \quad 0.0 \% \quad 0.6 \%$ $0.00[0.00 ; 312.69] \quad 0.0 \% \quad 0.9 \%$ $0.00 \quad[0.00 ; 69.17] \quad 0.1 \% \quad 3.5 \%$ $0.00 \quad[0.00 ; 68.41] \quad 0.1 \% \quad 3.6 \%$ $99.35[18.73 ; 243.56] \quad 0.3 \% \quad 6.3 \%$ $0.00[0.00 ; 30.18] \quad 0.3 \% \quad 6.5 \%$ $0.00 \quad[0.00 ; 27.91] \quad 0.3 \% \quad 6.8 \%$ $0.00[0.00 ; 24.40] \quad 0.4 \% \quad 7.4 \%$

$7.89 \quad[2.84 ; 15.48] \quad 7.1 \%$

$25.42[18.54 ; 33.39] \quad 16.5 \% \quad 18.0 \%$

$2.14[1.24 ; 3.28] \quad 74.2 \% \quad 18.4 \%$

$4.75[3.53 ; 6.14] 100.0 \% \quad 100.0 \%$

C Overall risk for SAE related to acupuncture among patients undergoing a treatment series Weight Weight

Study patients with SAE total patients Risk per 10000 patients Events $95 \%-\mathrm{Cl}$ (fixed) (random)

Wen 2016

Leung 2009

Yamashita 2000

da Silva 2014

Furuse 2017

MacPherson 2004

Melchart 2004

Weidenhammer 2008 ther

$\begin{array}{lrr}0.00[0.00 ; 79.82] & 0.0 \% & 0.2 \% \\ 0.00[0.00 ; 37.76] & 0.0 \% & 0.3 \% \\ 0.00[0.00 ; 24.54] & 0.0 \% & 0.5 \% \\ 0.00[0.00 ; 8.30] & 0.1 \% & 1.5 \% \\ 0.00[0.00 ; 4.40] & 0.2 \% & 2.7 \% \\ 4.73[0.89 ; 11.58] & 0.6 \% & 7.2 \% \\ 0.61[0.22 ; 1.20] & 9.9 \% & 37.3 \% \\ 0.19[0.11 ; 0.29] & 89.1 \% & 50.3 \%\end{array}$

Fixed effect model

Random effects model

Heterogeneity: $I^{2}=41 \%, \tau^{2}<0.0001, p=0.11$

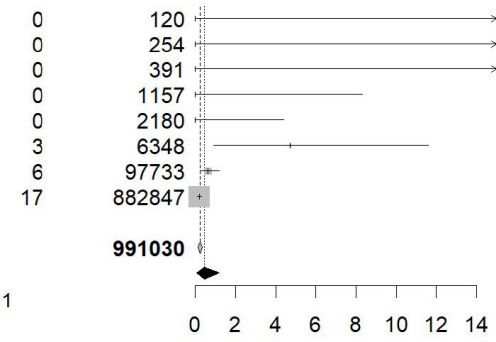

$0.23[0.15 ; 0.34] 100.0 \%$

$0.45[0.06 ; 1.18] \quad--\quad 100.0 \%$

D Overall risk for SAE related to acupuncture per treatment

treatments with SAE total treatments

Risk per $1 \mathrm{e}+06$ treatments Events

Weight Weight Study

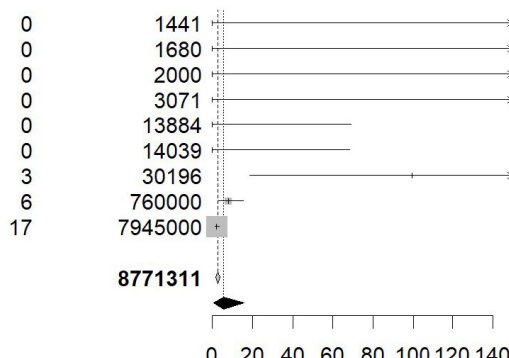

\begin{tabular}{|c|c|c|}
\hline 0.00 & {$[0.00 ; 666.31]$} & $0.0 \%$ \\
\hline 0.00 & {$[0.00 ; 571.54]$} & $0.0 \%$ \\
\hline 0.00 & {$[0.00 ; 480.11]$} & $0.0 \%$ \\
\hline 0.00 & {$[0.00 ; 312.69]$} & $0.0 \%$ \\
\hline 0.00 & {$[0.00 ; 69.17]$} & $0.2 \%$ \\
\hline 0.00 & {$[0.00 ; 68.41]$} & $0.2 \%$ \\
\hline 9.35 & {$[18.73 ; 243.56]$} & $0.3 \%$ \\
\hline 7.89 & {$[2.84 ; 15.48]$} & $8.7 \%$ \\
\hline 2 & {$[1.24 ; 3.28]$} & $0.6 \%$ \\
\hline & $\begin{array}{l}{[1.62 ; 3.74]} \\
{[0.50 ; 15.67]}\end{array}$ & \\
\hline
\end{tabular}

Random effects model

Heterogeneity: $I^{2}=42 \%, \tau^{2}<0.0001, p=0.09$

$0 \quad 2040 \quad 60 \quad 80100120140$

Figure 4 Meta-analyses of the overall risk of SAEs related to acupuncture. Summary risk estimates for SAEs were calculated as the number of SAE cases relative to the total number of patients or treatments, respectively. Data from the article published by Weidenhammer et al in $2008^{46}$ refer to the AE reports of the therapists. SAE, serious adverse event.

an acupuncture series were bleeding events, pain at the needling site, other local AEs, vegetative reactions, aggravation of symptoms, and events related to the central nervous system. Summary risk estimates for bleeding events, needle site pain, vegetative reactions, and aggravation of symptoms also ranged from $1 \%$ to $5 \%$ of treatments, while the meta-analysis of symptoms related to the central nervous system per acupuncture treatment resulted in a risk of 2 in 1000 treatments. AEs estimated to be uncommon with summary risk estimates of 1-7 out of 1000 patients undergoing an acupuncture series were symptoms of the peripheral nervous system, pain distant 
Table 3 Causality assessment of SAEs as reported in the included articles

\begin{tabular}{|c|c|c|}
\hline Sudy & SAEs & Causality \\
\hline \multicolumn{3}{|c|}{ Endres et al $2004^{33}$} \\
\hline & Death & Unlikely \\
\hline & Fall or trauma, with or without fracture & Possible \\
\hline & Acute general infection with hospitalisation & Unlikely \\
\hline & Allergic reaction to concomitant medication (atopy) & Possible \\
\hline & Stroke with hospitalisation & Unlikely \\
\hline & Cardiovascular problems (hospital admission) & Possible \\
\hline & Intervertebral disk prolapse, pain exacerbation with hospital admission & Unclassifiable \\
\hline & Malignant parotid tumour (hospital admission) & Unlikely \\
\hline & Hospitalisation (unknown reasons) & Unclassifiable \\
\hline
\end{tabular}

Weidenhammer et al 2008 ther. $^{46}$

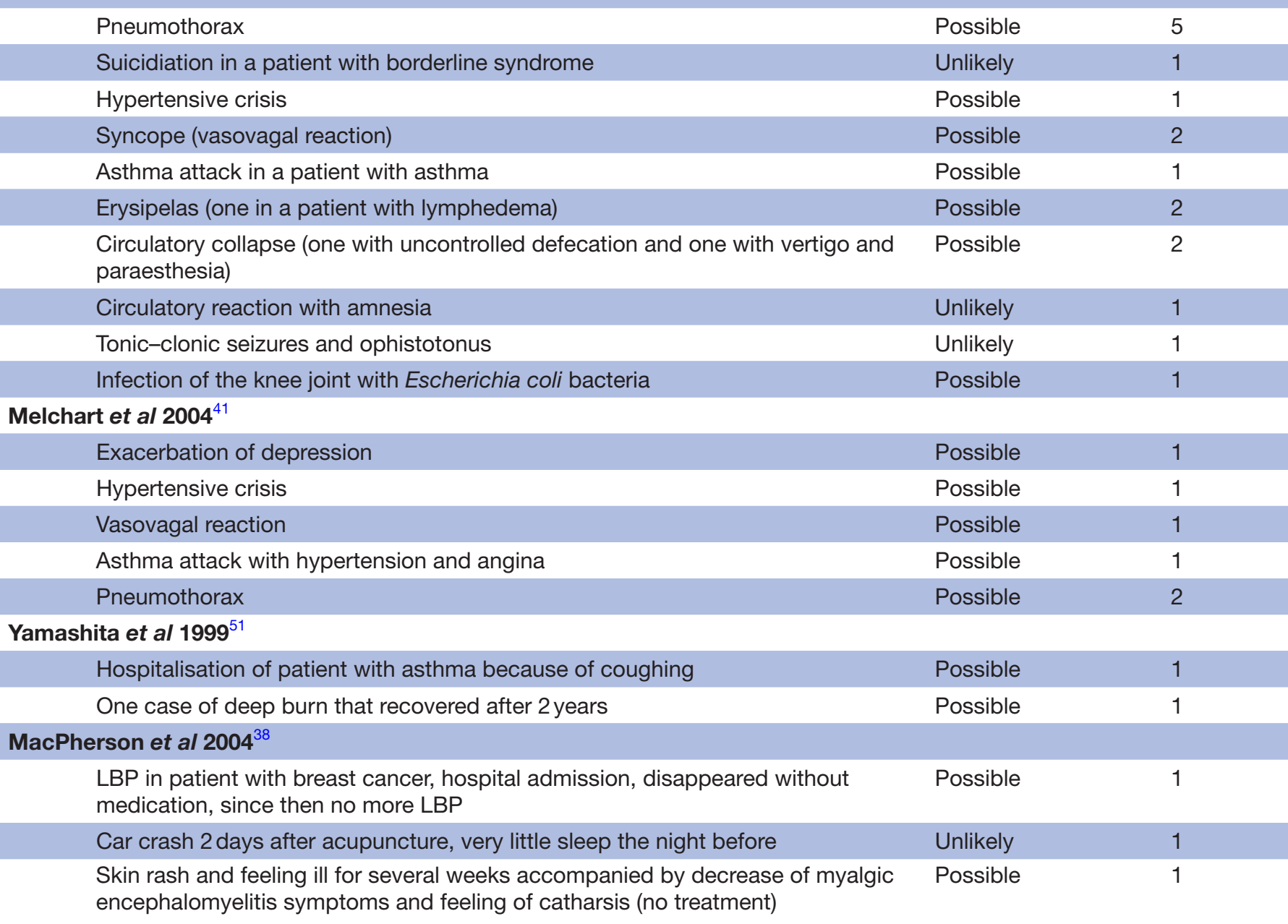

The total number of SAEs as well as the total number of treatments in each study can be identified from figure 4 . LBP, low back pain; SAE, serious adverse event.

to the needling site, gastrointestinal or gynaecological symptoms, headache, cardiovascular symptoms, affection of the motor system, generalised skin reactions, adverse emotional reactions, and sleeping problems. Symptoms affecting the peripheral nervous system, distant pain, as well as gastrointestinal or gynaecological symptoms were estimated to occur in 1-7 out of 1000 treatments; headache, cardiovascular and motor symptoms, as well as adverse emotional reactions were estimated to occur only in 1-8 out of 10000 treatments. The risk of respiratory AE was estimated to be rare with a summary risk estimate of 4 out of 10000 patients undergoing an acupuncture series and three out of 10000 treatments. Summary risk estimates for AEs caused by therapists' malpractice and burns 


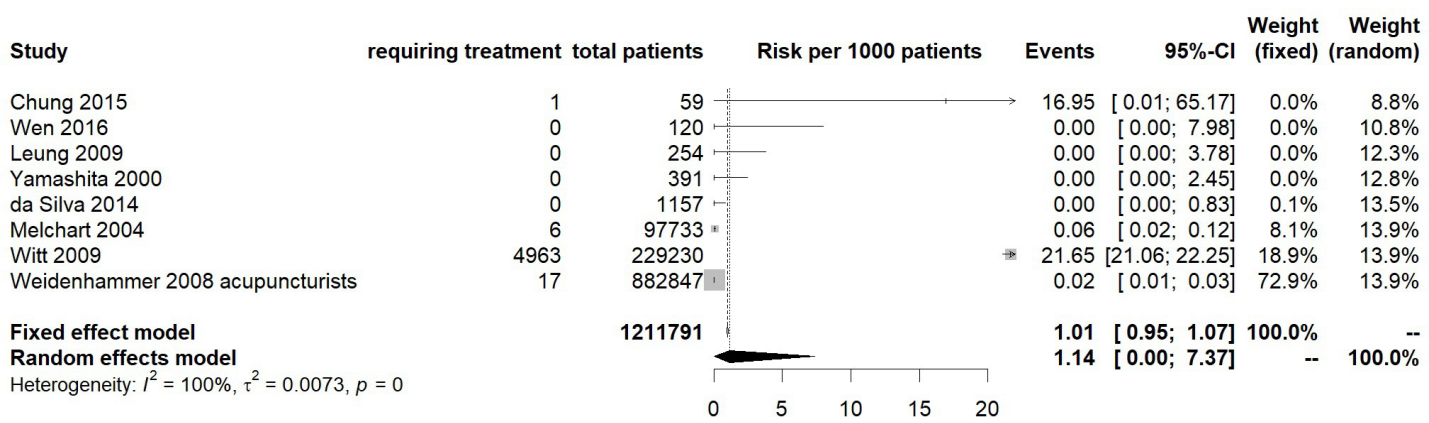

Figure 5 Meta-analyses of the overall risk of AEs requiring treatment. Summary risk estimates for AEs requiring treatment were calculated as the number of patients with such $\mathrm{AE}$ relative to the total number of patients. AE, adverse event.

caused by moxibustion were one to two in 1000 patients undergoing an acupuncture series and 2 in 10000 to one in 1000 treatments, respectively.

Some of the studies showed outlying incidences for particular types of minor AE. List and Helkimo observed at least one vegetative reaction in the course of an acupuncture series for craniomandibular disorder in over half of the patients $(58.6 \%),{ }^{37}$ and MacPherson and Thomas reported vegetative reactions in $27.9 \%$ of treatments. ${ }^{39}$ These findings exceed the frequency of vegetative reactions of up to $13.6 \%$ of patients identified in the remaining studies and were mainly based on patient reports of abnormal tiredness after treatment. List $e t$ al also report the highest incidence of aggravation of symptoms with $93 \%$ of patients with craniomandibular disorder (CMD) as well as the highest frequency of needle site pain with $44.8 \%$ of patients. This was followed by an RCT with $32.2 \%$ of patients suffering from needle site pain ${ }^{31}$ and a cohort study among patients with chronic pain of which $10 \%$ suffered aggravation of symptoms after receiving acupuncture. ${ }^{42}$ The remaining 19 articles reported incidences smaller than $3 \%$ for aggravation of symptoms and $14 \%$ for needle site pain.

\section{DISCUSSION}

\section{Overall risk of acupuncture-related AEs}

To date, this is the first systematic review of prospective studies that provides summary risk estimates for acupuncture-related AEs derived from meta-analyses. The obtained results suggest that an $\mathrm{AE}$ can be expected in every 10th patient that undergoes a series of acupuncture treatments and, overall, in every 13th treatment. Minor AEs were common and represented the large majority of reported AEs. About half of the reported minor AEs are usually mild and transient or might even be regarded as part of the acupuncture treatment or therapeutically intended reactions (bleeding, needle site pain, and flare around the needle site). ${ }^{21}$ SAEs can be expected rarely in about every 10000th patient in the course of an acupuncture series and, overall, in every 125000 th treatment. Sensitivity analyses excluding studies with zero SAE incidences still suggest SAEs being rare (every 7000th patient and every 60000th treatment) particularly in comparison to SAE risk associated with pharmacological treatments. ${ }^{165354}$ This risk was $30 \%$ to $50 \%$ lower when only considering studies reporting on SAEs with a plausbly causal relationship to acupuncture. AEs requiring treatment occur uncommonly in about every 900th treatment, but additional AEs are likely to also have involved medical decision making about further diagnostics and follow-up. With meta-analyses for the overall risk of acupuncturerelated AEs covering over 845637 patients undergoing more than 7.4 million treatments and for the risk of SAEs covering more than 1.2 million patients and 10.6 million treatments, the amount of data is equivalent to that on the safety of, for example, common analgesics. ${ }^{55} 56$ This work augments insights on acupuncture-related AEs from previous reviews with either narrow eligibility criteria or focusing on case reports. ${ }^{17}$ It includes data from the largest and most rigorous trials on acupuncture safety, for example, from the large nationwide cohort studies conducted in the UK and Germany, which had not yet been aggregated. ${ }^{33} 38-41464849$ Thus, our results provide rigorous support for the previously drawn conclusion ${ }^{225758}$ that acupuncture is among the safe treatments in medicine with SAEs occurring rarely and half of the common minor AEs being mild and transient. The uncommon AEs requiring treatment necessitate solid medical competence of acupuncturists.

\section{Types of AEs related to acupuncture and implications for} medical education of acupuncturists

Common minor AEs were bleeding, needle site pain, other local reactions at the needling site, vegetative reactions, aggravation of symptoms, and AEs related to the central nervous system (1-5 out of 100 patients). This is in line with other reviews ${ }^{22} 59$ also on auricular ${ }^{60}$ and paediatric acupuncture. ${ }^{58}$ All other types of minor AEs can be regarded as uncommon (1-7 per 1000 patients), despite respiratory reactions that occurred very rarely (4 per 10000 patients). SAEs most often reported were pneumothorax, strong cardiovascular or vasovagal reactions, and fall or trauma with one to three cases in one million treatments. Several other sometimes fatal SAEs repeatedly described in case reports were not observed in the included studies, for example, traumatic injuries of inner organs, local and systemic infections, subarachnoid bleeding, infective endocarditis, and cardiac tamponade. ${ }^{61-65}$ This is likely due to the fact that 


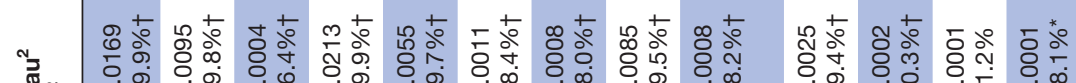

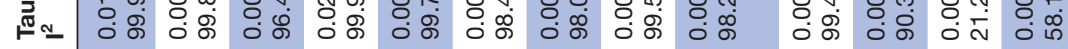

$\overline{\mathrm{o}}$

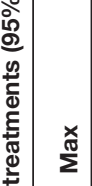

우

ఏ

焉

年

焉

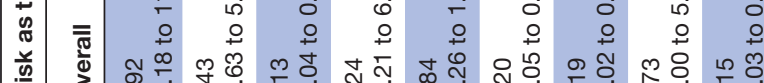

竞

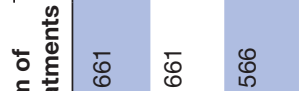

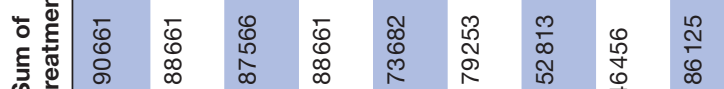

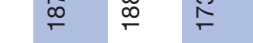

$\stackrel{\infty}{\frac{0}{2}}$

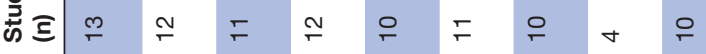

ح 䨪

ธิ

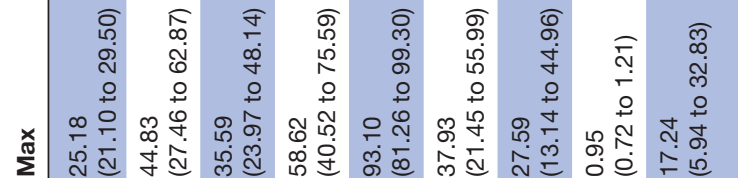

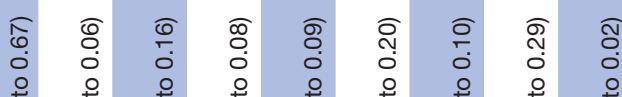

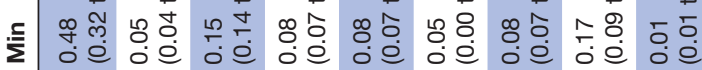

สำ

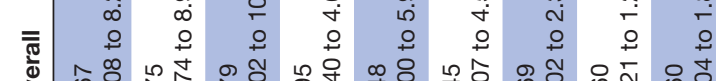

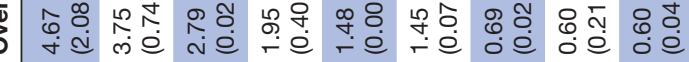

है

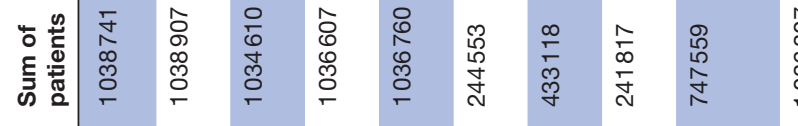

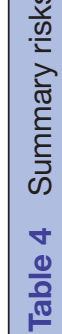

$\stackrel{0}{\frac{0}{3}}$

कำ

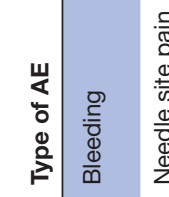

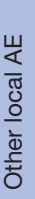

$\begin{array}{llll}\widehat{N} & \overline{0} & \widehat{m} & \overline{0} \\ 0 & 0 & 0 \\ 0 & 0 & 0 \\ 0 & 0 & 0 & 0\end{array}$

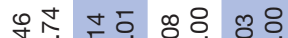

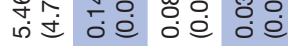

हิ

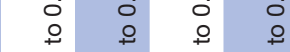

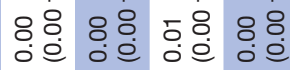

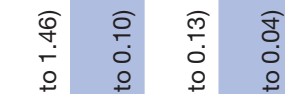

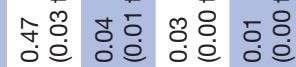

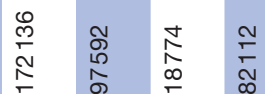

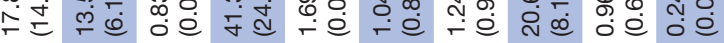

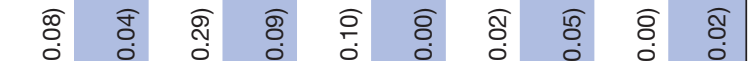

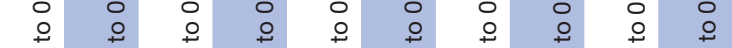

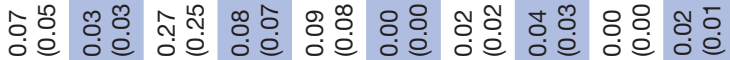

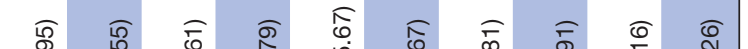

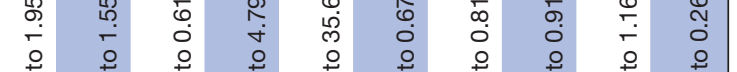
ก็ ơ 
acupuncturists in most of the studies were well trained, as SAEs are claimed to be avoidable by proper acupuncture training and practice. Concordantly, cases of acupuncture malpractice were uncommon in the included trials.

\section{Heterogeneity between studies}

Possible causes of the substantial heterogeneity observed in all meta-analyses are differences in patient populations, needling regimens, $\mathrm{AE}$ definition, and $\mathrm{AE}$ assessment. Sensitivity analyses of trials reporting on adverse reactions only with a plausible relationship to acupuncture resulted in marginally lower overall $\mathrm{AE}$ risk estimates but reduced the SAE risk from one to 0.45 cases in 10000 patients and from eight to five cases in one million treatments. Thus, reporting of SAEs irrespective of the relationship to acupuncture is surely more conservative but likely to cause risk overestimation. In line with this, the causality of more than half of the SAEs was rated as unlikely or unclassifiable by two independent acupuncture experts.

The variety of combinations of further patient-, treatment-, and assessment-related factors prevented meaningful subgrouping of studies for additional sensitivity analyses, and the likeliness of their contribution to the observed heterogeneity makes formal assessment for publication bias unadvisable. ${ }^{66}$ However, some distinct observations are worth discussing. Certain patient populations might be at higher risk of experiencing acupuncture-related $\mathrm{AE}$; for example, in one study conducted among patients with CMD, AEs were prominently frequent. ${ }^{37}$ The role of acupuncture regimens in explaining heterogeneity could not be determined due to the limited information about number, location, and stimulation of needles. In contrast, the number of treatments per acupuncture series and study type seemed not to have impacted reported $\mathrm{AE}$ incidences.

Further possible causes of heterogeneity are differences in contrasting AEs from therapeutically intended reactions that form part of acupuncture treatment; for example, in contrast to international consensus, ${ }^{18}$ aggravated symptoms were not or only in part counted as AEs in two studies. ${ }^{32}{ }^{48}$ Local reactions such as bleeding, pain, and flare at the needling site, which represented half of the AEs reported, are referred to as beneficial signs in standard acupuncture textbooks and by authors themselves. ${ }^{20} 33$ As the principle of acupuncture is to induce endogenous antinociceptive mechanisms and antiinflammatory humoral responses through microtrauma of the skin and tissue, it can be argued that moderate local reactions are indeed desired reactions indicating an induction of regulative processes. Mild pain and a flare at the needling site have been linked to important neurophysiological mechanisms of acupuncture.$^{21}$ Additionally, aching or soreness at the needling site might be part of the intended deqi sensation (propagated sensation along the channels) supposedly related to acupuncture effectiveness. ${ }^{19}$ The loss of small drops of blood upon needle withdrawal is interpreted as a sign of the patient's constitution called 'excess' or 'excess heat' in traditional Chinese medicine terminology and was suggested not to be interpreted as $\mathrm{AE}^{67}$ On the other hand, standard textbooks explicitly explain needling techniques avoiding pain and bleeding. ${ }^{20} 68$ This debate calls for a uniform, internationally recognised consensus on the definition of local acupuncture reactions as AEs, for example, according to their quality and intensity.

In addition, included studies differed in reporters (acupuncturists, patients, acupuncturists also questioning patients, and independent assessors), the type of documentation (selection list, open questions, or a combination of both), and assessment time points. Due to the large variability of combinations, the individual impact of these factors could not be estimated, but literature suggests that patients report more AEs than therapists, ${ }^{69}$ and that open questions presented to patients lead to lower risk estimates than the presentation of a selection list of possible AEs. ${ }^{31}$ Thus, standardised AE assessment methods should be established for acupuncture studies.

\section{Risk of bias in included studies}

Although large prospective studies are among the most important sources of safety data, they come with the known risk of information, selection, and confounding bias. ${ }^{70}$ Risk of information bias was mostly related to poor reporting of acupuncture regimens and the discrepancies in $\mathrm{AE}$ definition and assessment. This is in line with the shortcoming identified for reporting of AEs in acupuncture RCTs. ${ }^{71}$ Possible causes of selection bias identified were mainly voluntary participation of practitioners, unsystematic patient selection, and study conductance in highly specialised institutions. Practical reasons make these causes of selection bias inherent to safety studies. They, however, are unlikely to importantly impair external validity, considering the large number of patients and treatments, the variety of countries in which studies were conducted, and the inclusion of different study designs. Future large-scale comparative safety studies, along with modern statistical methods for confounder adjustment, could be used to contrast $\mathrm{AE}$ risks of acupuncture and other treatments and to identify patient and treatment characteristics associated with AEs in real-world clinical settings. ${ }^{72}$

\section{Limitations}

First, it is debatable whether studies should be summarised irrespective of whether AEs not necessarily related to acupuncture or adverse reactions likely caused by acupuncture were reported. In order to provide the most comprehensive information possible, respective sensitivity analyses were conducted. Another limitation with regard to the inclusion criteria is the restriction to articles published in German or English as many studies on acupuncture are published in Chinese. Additionally, the risk estimates for the different types of minor AEs are likely to be slightly overestimated and should be interpreted as a rough indication that allows distinguishing frequent from less frequent acupuncture-related minor 
AEs. In categorising the minor AEs, it was disregarded that several different AEs falling in one category could have occurred in the same patient or during the same treatment. Also, calculations of risks in treatments with $\mathrm{AE}$ per total number of treatments could not adjust for the fact that multiple AE assessments in the same patient are not independent. Furthermore, zero incidences of certain types of AEs were not available. Finally, the causality assessment presented for SAEs is limited to expert opinions and is only based on the information provided in the respective articles. Such an evaluation does not replace a rigorous causality assessment that would involve querying patients and therapists.

\section{Clinical implications}

Patients should be informed that acupuncture commonly causes minor AEs, but rarely SAEs. Examples for SAEs should at least cover the most frequent ones, pneumothorax, and strong cardiovascular or vasovagal reactions potentially leading to fall or trauma, along with the respective incidence of one to three per million treatments. Patients should also be made aware of the fact that a great part of the minor AEs are either very mild or even intended effects that indicate a beneficial physiological reaction. However, they should be encouraged to report any prolonged discomfort or pain that are to be avoided during treatment. Acupuncturists should carefully balance treatment intensity according to patients' reactions in order to minimise AEs. They should assess local AEs upon needle withdrawal and query patients about AEs directly after treatment as well as at the subsequent visit. Therapists should be aware that, although uncommon, AEs requiring treatment can be expected and necessitate medical decision making. Medical competence is particularly required for the indication of acupuncture in patients at high risk of AEs or those in which AEs could lead to particular aversive outcomes, such as pregnant women, elderly and patients with cardiovascular comorbidities. In these patients, acupuncture can be especially beneficial, as conventional treatments, for example, with analgesics are often limited by side effects or drug interactions, but selection of acupuncture regimens needs to involve careful risk-benefit considerations. Theses medical competences required to provide optimal patient safety should also be reflected by acupuncture education standards and regulations. At this, policy makers should take into account the worldwide popularity of acupuncture which is likely to further increase, as its scientific level of evidence has led to more than 4000 practice guidelines recommending acupuncture for different mostly pain indications. ${ }^{69}$

\section{CONCLUSION}

Acupuncture can be considered among the safer treatments in medicine. It rarely causes SAEs, and the majority of the common minor AEs are very mild. AEs requiring medical management are uncommon. For optimal patient safety, acupuncture education standards regulations should reflect that solid medical competence of acupuncturists is required to manage AEs properly and to minimise the risk of malpractice. Clinical and methodological heterogeneity calls for an international consensus on AE assessment tools in acupuncture studies and criteria for differentiating acupuncture-related AEs from therapeutically desired reactions as well as identification of patient-related risk factors for acupuncturerelated AEs. In particular, comparative safety studies are needed to contrast acupuncture to standard care in its main indications.

Acknowledgements We thank Mrs Luise Möhring and Dr Barbara Jopen-Wolff from the Multidisciplinary Pain Centre, Department for Anaesthesiology, University Hospital LMU Munich. Mrs Möhring assisted in article screening and Dr JopenWolff participated in the causality assessment. The contribution of Mrs Wenyue Zhang during the planning phase was made possible by the support of the China Scholarship Council of the LMU Munich.

Contributors $\mathrm{DI}, \mathrm{PB}$ and WZ defined the research question as well as inclusion and exclusion criteria for this systematic review. WZ, TS and PB were responsible for article screening, data extraction and classifications of adverse events. TS and PB performed the quality assessment. Questions and discrepancies were discussed among all authors until consent was achieved. PB conducted the meta-analyses and designed the tables and figures. All authors contributed to drafting the manuscript and approved its final version for publication. PB, the corresponding author, attests that all listed authors meet authorship criteria and that no others meeting the criteria have been omitted. As the senior author, $\mathrm{DI}$ is the guarantor of the work presented in this article and accepts full responsibility for the finished article, has access to any data and controlled the decision to publish.

Funding The authors have not declared a specific grant for this research from any funding agency in the public, commercial or not-for-profit sectors.

Competing interests DI reports receiving honorarium and travel costs from nonprofit academic organisations, physician chambers and universities for teaching and lecturing, and serving as president of the German Medical Acupuncture Association (Deutsche Ärztegesellschaft für Akupunktur, DÄGfA, a non-profit medical association). PB declares receiving honorarium and travel costs from nonprofit academic organisations and universities for teaching and lecturing and being a member of the scientific advisory board of the DÄGFA. WZ and TS declare no other relationships or activities that could appear to have influenced the submitted work.

Patient consent for publication Not required.

Provenance and peer review Not commissioned; externally peer reviewed.

Data availability statement Data are available upon reasonable request. The full set of extracted data and the R-code underlying the meta-analyses are available from the corresponding and senior author (Petra.Baeumler@med.uni-muenchen.de, Dominik.Irnich@med.uni-muenchen.de).

Supplemental material This content has been supplied by the author(s). It has not been vetted by BMJ Publishing Group Limited (BMJ) and may not have been peer-reviewed. Any opinions or recommendations discussed are solely those of the author(s) and are not endorsed by BMJ. BMJ disclaims all liability and responsibility arising from any reliance placed on the content. Where the content includes any translated material, BMJ does not warrant the accuracy and reliability of the translations (including but not limited to local regulations, clinical guidelines, terminology, drug names and drug dosages), and is not responsible for any error and/or omissions arising from translation and adaptation or otherwise.

Open access This is an open access article distributed in accordance with the Creative Commons Attribution Non Commercial (CC BY-NC 4.0) license, which permits others to distribute, remix, adapt, build upon this work non-commercially, and license their derivative works on different terms, provided the original work is properly cited, appropriate credit is given, any changes made indicated, and the use is non-commercial. See: http://creativecommons.org/licenses/by-nc/4.0/.

ORCID iD

Petra Bäumler http://orcid.org/0000-0002-3262-2993 


\section{REFERENCES}

1 Ammon K, Cardini F, Daig U. Final Report of CAMbrella Work Package 5 - Helath Technology Assessment (HTA) and a map of CAM provision in the EU. CAMbrella - A pan-European research network for Complementary and Alternative Medicine (CAM), 2013. Available: https://phaidra.univie.ac.at/view/o:300096

2 British Acupuncture Council. Acupuncture practitioners in the UK, 2016. Available: https://www.acupuncture.org.uk/public-content/ about-the-bacc/4115-acupuncture-practitioners-in-the-uk.html

3 Cui J, Wang S, Ren J, et al. Use of acupuncture in the USA: changes over a decade (2002-2012). Acupunct Med 2017;35:200-7.

4 Vickers AJ, Vertosick EA, Lewith G, et al. Acupuncture for chronic pain: update of an individual patient data meta-analysis. J Pain 2018;19:455-74.

5 Linde K, Allais G, Brinkhaus B, et al. Acupuncture for the prevention of episodic migraine. Cochrane Database Syst Rev 2016;6:Cd001218.

6 Linde K, Allais G, Brinkhaus B, et al. Acupuncture for the prevention of tension-type headache. Cochrane Database Syst Rev 2016;4:Cd007587.

7 Tedesco D, Gori D, Desai KR, et al. Drug-Free interventions to reduce pain or opioid consumption after total knee arthroplasty: a systematic review and meta-analysis. JAMA Surg 2017;152:e172872.

8 Sun Y, Gan TJ, Dubose JW, et al. Acupuncture and related techniques for postoperative pain: a systematic review of randomized controlled trials. Br J Anaesth 2008;101:151-60.

9 Lee A, Chan SKC, Fan LTY. Stimulation of the wrist acupuncture point PC6 for preventing postoperative nausea and vomiting. Cochrane Database Syst Rev 2015;11:Cd003281.

10 Feng S, Han M, Fan Y, et al. Acupuncture for the treatment of allergic rhinitis: a systematic review and meta-analysis. Am J Rhinol Allergy 2015;29:57-62

11 Yang A, Wu HM, Tang J-L, et al. Acupuncture for stroke rehabilitation. Cochrane Database Syst Rev 2016:Cd004131.

12 Smith CA, Armour M, Lee MS, et al. Acupuncture for depression. Cochrane Database Syst Rev 2018;3:Cd004046.

13 Hershman DL, Unger JM, Greenlee H, et al. Effect of acupuncture vs sham acupuncture or Waitlist control on joint pain related to aromatase inhibitors among women with early-stage breast cancer: a randomized clinical trial. JAMA 2018;320:167-76.

14 Brinkhaus B, Roll S, Jena S, et al. Acupuncture in patients with allergic asthma: a randomized pragmatic trial. J Altern Complement Med 2017;23:268-77.

15 Whiskey E, Taylor D. A review of the adverse effects and safety of noradrenergic antidepressants. J Psychopharmacol 2013;27:732-9.

16 Carter GT, Duong V, Ho S, et al. Side effects of commonly prescribed analgesic medications. Phys Med Rehabil Clin N Am 2014:25:457-70.

17 Chan MWC, Wu XY, Wu JCY, et al. Safety of acupuncture: overview of systematic reviews. Sci Rep 2017;7:3369.

18 White A, Boon H, Alraek T, et al. Reducing the risk of complementary and alternative medicine (cam): challenges and priorities. Eur J Integr Med 2014;6:404-8.

19 Ren Y-L, Guo T-P, Du H-B, et al. A survey of the practice and perspectives of Chinese acupuncturists on deqi. Evid Based Complement Alternat Med 2015;2015:1-8.

20 Shanghai College of Traditional Medicine. Acupuncture - a comprehensive text. Seattle, USA: Eastland Press, 1981.

21 Zhu H. Acupoints initiate the healing process. Med Acupunct 2014;26:264-70.

22 Ernst E, White AR. Prospective studies of the safety of acupuncture: a systematic review. Am J Med 2001;110:481-5.

23 University of York Y, UK. International prospective register of systematic reviews (Prospero). Available: https://www.crd.york.ac.uk/ prospero

24 Moher D, Liberati A, Tetzlaff J, et al. Preferred reporting items for systematic reviews and meta-analyses: the PRISMA statement. $J$ Clin Epidemiol 2009;62:1006-12.

25 Stroup DF, Berlin JA, Morton SC, et al. Meta-analysis of observational studies in epidemiology: a proposal for reporting. meta-analysis of observational studies in epidemiology (moose) group. JAMA 2000;283:2008-12.

26 European Medicines Agency. Guideline for good clinical practice E6(R2), 2016. Available: https://www.ema.europa.eu/en/documents/ scientific-guideline/ich-e-6-r2-guideline-good-clinical-practice-step5_en.pdf

27 Uppsla Monitoring Centre. WHO-UMC system for standardised case causality assessment, 2013. Available: https://www.who.int/ publications/m/item/WHO-causality-assessment

28 Council for International organizations of medical sciences - CIOMS. Guidelines for preparing core Clinical-Safety information on drugs second edition - report of CIOMS working groups III and V, 1999. Available: https://cioms.ch/shop/product/guidelines-preparing-coreclinical-safety-information-drugs-second-edition-report-ciomsworking-groups-iii-v/

29 Faillie J-L, Ferrer P, Gouverneur A, et al. A new risk of bias checklist applicable to randomized trials, observational studies, and systematic reviews was developed and validated to be used for systematic reviews focusing on drug adverse events. J Clin Epidemiol 2017;86:168-75.

30 Schwarzer G. meta: $\{A\} n\{R\}$ package for meta-analysis. $R$ News 2007;7:40-5.

31 Chung K-F, Yeung W-F, Yu Y-M, et al. Adverse events related to acupuncture: development and testing of a rating scale. Clin J Pain 2015;31:922-8.

32 da Silva JBG, Saidah R, Megid CBC, et al. Adverse events following acupuncture: a prospective survey of 13,884 consultations in a university out-patient acupuncture training clinic in Brazil. Eur $J$ Integr Med 2014;6:488-91.

33 Endres HG, Molsberger A, Lungenhausen M, et al. An internal standard for verifying the accuracy of serious adverse event reporting: the example of an acupuncture study of 190,924 patients. Eur J Med Res 2004;9:545-51.

34 Ernst G, Strzyz H, Hagmeister $\mathrm{H}$. Incidence of adverse effects during acupuncture therapy-a multicentre survey. Complement Ther Med 2003:11:93-7.

35 Furuse N, Shinbara $\mathrm{H}$, Uehara A, et al. A multicenter prospective survey of adverse events associated with acupuncture and moxibustion in Japan. Med Acupunct 2017;29:155-62.

36 Leung P-chung, Zhang L, Cheng K-fai. Acupuncture: complications are preventable not adverse events. Chin J Integr Med 2009;15:229-32.

37 List T, Helkimo M. Adverse events of acupuncture and occlusal splint therapy in the treatment of craniomandibular disorders. Cranio 1992;10:318-26.

38 Macpherson H, Scullion A, Thomas KJ, et al. Patient reports of adverse events associated with acupuncture treatment: a prospective national survey. Qual Saf Health Care 2004;13:349-55.

39 MacPherson H, Thomas K. Short term reactions to acupuncture-a cross-sectional survey of patient reports. Acupunct Med 2005;23:112-20.

40 MacPherson $\mathrm{H}$, Thomas $\mathrm{K}$, Walters $\mathrm{S}$, et al. A prospective survey of adverse events and treatment reactions following 34,000 consultations with professional acupuncturists. Acupunct Med 2001;19:93-102.

41 Melchart D, Weidenhammer W, Streng A, et al. Prospective investigation of adverse effects of acupuncture in 97733 patients. Arch Intern Med 2004;164:104-5.

42 Melchart DV, Hager S, Weidenhammer W. Adverse effects and concomitant symptoms associated with acupuncture treatment - A pilot study. Akupunktur 1998;26:87-92.

43 Odsberg A, Schill U, Haker E. Acupuncture treatment: side effects and complications reported by Swedish physiotherapists. Complement Ther Med 2001;9:17-20.

44 Park J-E, Lee MS, Choi J-Y, et al. Adverse events associated with acupuncture: a prospective survey. J Altern Complement Med 2010;16:959-63.

45 Park S-U, Ko C-N, Bae H-S, et al. Short-term reactions to acupuncture treatment and adverse events following acupuncture: a cross-sectional survey of patient reports in Korea. $J$ Altern Complement Med 2009;15:1275-83.

46 Weidenhammer W, Streng A, Melchart D, et al. Unerwünschte Wirkungen und Komplikationen bei Akupunkturbehandlung: Ergebnisse Der großen Beobachtungsstudie Im Rahmen des Modellvorhabens Der Ersatzkassen. Dtsch Zeitschrift für Akupunkt 2008;51:6-14.

47 Wen Y, Zhang C, Zhao X-F, et al. Safety of different acupuncture manipulations for posterior circulation ischemia with vertigo. Neural Regen Res 2016;11:1267-73.

48 White A, Hayhoe S, Hart A, et al. Survey of adverse events following acupuncture (SAFA): a prospective study of 32,000 consultations. Acupunct Med 2001;19:84-92.

49 Witt CM, Pach D, Brinkhaus B, et al. Safety of acupuncture: results of a prospective observational study with 229,230 patients and introduction of a medical information and consent form. Forsch Komplementmed 2009;16:91-7.

50 Yamashita $\mathrm{H}$, Tsukayama $\mathrm{H}$, Hori $\mathrm{N}$, et al. Incidence of adverse reactions associated with acupuncture. J Altern Complement Med 2000;6:345-50.

51 Yamashita H, Tsukayama H, Tanno Y, et al. Adverse events in acupuncture and moxibustion treatment: a six-year survey at a national clinic in Japan. J Altern Complement Med 1999;5:229-36. 
52 Zhao L, Zhang F-wen, Li Y, et al. Adverse events associated with acupuncture: three multicentre randomized controlled trials of 1968 cases in China. Trials 2011;12:87.

53 Degner D, Grohmann R, Kropp S, et al. Severe adverse drug reactions of antidepressants: results of the German multicenter drug surveillance program AMSP. Pharmacopsychiatry 2004;37 Suppl 1:S39-45.

54 Singh G. Gastrointestinal complications of prescription and overthe-counter nonsteroidal anti-inflammatory drugs: a view from the ARAMIS database. arthritis, rheumatism, and aging medical information system. Am J Ther 2000;7:115-21.

55 Trelle S, Reichenbach S, Wandel S, et al. Cardiovascular safety of non-steroidal anti-inflammatory drugs: network meta-analysis. BMJ 2011;342:c7086.

56 Martín Arias LH, Martín González A, Sanz Fadrique R, et al. Gastrointestinal safety of coxibs: systematic review and metaanalysis of observational studies on selective inhibitors of cyclooxygenase 2. Fundam Clin Pharmacol 2019;33:134-147.

57 Wang C, Tan B, Williams A. Safety and side effects of acupuncture therapy in Australia: a systematic review. Eur J Integr Med 2019.

58 Adams D, Cheng F, Jou H, et al. The safety of pediatric acupuncture: a systematic review. Pediatrics 2011;128:e1575-87.

59 Wang CC, Tan J-Y, Williams A. Safety and side effects of acupuncture therapy in Australia: a systematic review. Eur $\mathrm{J}$ Integr Med 2019;27:81-9.

60 Tan J-Y, Molassiotis A, Wang T, et al. Adverse events of auricular therapy: a systematic review. Evid Based Complement Alternat Med 2014;2014:1-20

61 Zhang J, Shang H, Gao X, et al. Acupuncture-related adverse events: a systematic review of the Chinese literature. Bull World Health Organ 2010;88:915-21.
62 Xu S, Wang L, Cooper E, et al. Adverse events of acupuncture: a systematic review of case reports. Evid Based Complement Alternat Med 2013;2013:1-15.

63 He W, Zhao X, Li Y, et al. Adverse events following acupuncture: a systematic review of the Chinese literature for the years 1956-2010. $J$ Altern Complement Med 2012;18:892-901.

64 Ernst E, Lee MS, Choi T-Y. Acupuncture: does it alleviate pain and are there serious risks? A review of reviews. Pain 2011;152:755-64.

65 Ullah W, Ahmad A, Mukhtar M, et al. Acupuncture-Related cardiac complications: a systematic review. J Invasive Cardiol 2019;31:E69-72.

66 Lau J, loannidis JPA, Terrin N, et al. The case of the misleading funnel plot. BMJ 2006;333:597-600.

67 Zhu HZ. Running a safe and successful acupuncture clinic. Edinburgh, London, New York, Oxford, Philadelphia, St Louis, Sydney, Toronto: Elsevier - Churchill Livingstone, 2006.

68 Deng L, Gan Y, He S. Chinese acupuncture and moxibustion. 2 edn. Beijing, China: Foreign Languages Press, 1999.

69 Schwaneberg T, Witt CM, Roll S, et al. Comparing physicians' and patients' reporting on adverse reactions in randomized trials on acupuncture-a secondary data analysis. BMC Complement Altern Med 2019;19:223.

70 Suissa S. Statistical methods in pharmacoepidemiology: advances and challenges. Stat Methods Med Res 2009;18:3-6.

71 Capili B, Anastasi JK, Geiger JN. Adverse event reporting in acupuncture clinical trials focusing on pain. Clin J Pain 2010;26:43-8.

72 Desai RJ, Franklin JM. Alternative approaches for confounding adjustment in observational studies using weighting based on the propensity score: a primer for practitioners. BMJ 2019;367:15657. 